\title{
Philipp Stoellger
}

\section{Das Wort vom Kreuz im Deutungsmachtkonflikt}

\section{Zur Genealogie der Theologie aus dem Geist der paulinischen Rhetorik}

\begin{abstract}
Starting from the concept of >Deutungsmacht (interpretational power) the origin of christian theology in the rhetoric of Paul is analyzed. The power of words against the words of power is distinguished to show, how spower (potentia) works: as the power of showing, saying and monstration. The pauline >word of the cross is a paradigm for such interpretational power, figuring and transfiguring Christ as the Crucified. The word of the cross is the origin of christian theology as rhetoric but always with the pretention to be autorized by God himself. The problems of autorization (apostolicity) seems to be a shift from the power of words to the words of power: a history of autorization, in which the shistoric Paul becomes the >canonical Paulı, the simaginary Paul and at last the spauline dispositive of the church. Who is speaking when Paul speaks?
\end{abstract}

\section{Einleitung: Sine vi, sed verbo}

Das Christentum ist keine Schrift- oder Buchreligion, sondern eine Wortreligion. Es hofft und vertraut auf die viva vox, auf die lebendige Rede der Verkündigung, auf Zeugnis und Erzählung, auf Gleichnis und Metapher, auf Anspruch und Anrede, Zuspruch und Zurede, und auch in der Theologie auf Rede und Argumentation - kurzum: Auf alles, was rhetorisch >wahrhaft, würdig und recht ` ist. Christlicher Glaube vertraut auf das Wort, statt auf Macht, gar auf Allmacht oder ähnliche metaphysische Fantasien. Das gilt für den >Verkehr der Christen mit Gott ‘ ebenso wie zwischenmenschlich in den Kirchen und Gemeinden - oder auch an der Universität: Als kritische Regel zumindest gilt >Wort statt Macht`. Daher hat ein treffendes Wort allemal mehr zu sagen, als einer, der qua Amt das Sagen zu haben meint. - Nur, wenn es so einfach wäre, könnte man hier beruhigt schließen.

Für die christliche Verkündigung gilt die Regel sine vi humana, sed verbo, oder im Deutschen (etwas erweitert): »ohn menschlichen Gewalt, sondern allein durch Gottes Wort « (CA 28). ${ }^{1}$ Das ist im Protestantismus zur normativen Bekenntnisformel geworden -

1 Vgl. Die Bekenntnisschriften der evangelisch-lutherischen Kirche, herausgegeben im Gedenkjahr der Augsburgischen Konfession 1930, 12. Auflage, Göttingen 1998, 123, 21-124, 9 (= Confessio Augustana, Artikel 28): Cum igitur de iurisdictione episcoporum quaeritur, discerni debet imperium ab ecclesiastica iurisdictione. Proinde secundum evangelium seu, ut loquuntur, de iure divino haec iurisdictio competit episcopis ut episcopis, hoc est his, quibus est commissum ministerium verbi et sacra- 
und gilt auch theologisch, in jedem Seminar oder jedem Gespräch ansonsten: Man möge sich doch bitte gewaltfrei auf das Wort verlassen, ihm vertrauen - in Glaube, Liebe und Hoffnung, dass das wohl wirken werde. Der universitäre ebenso wie der kirchliche und theologische Gewaltverzicht beruht auf dem Vertrauen auf das Wort und seine Wirkung, seine vergemeinschaftende, kommunikative Wirkung. Das Wort ist immer (auch) verbum efficax: wirksames Wort - so oder so. Wer spricht - der wirkt, oder will zumindest wirken. Wer sagt, der tut und zeigt etwas. Und das ist nie folgenlos.

Gewaltverzicht ist sicher richtig und wichtig. Physische, psychische ebenso wie institutionelle oder verbale Gewalt hat (normativ gesagt) >draußen` zu bleiben - in religiöser ebenso wie theologischer Rede. Sine vi sed verbo ist eine Exklusionsformel: Sie benennt, was immer wieder ausgeschlossen werden muss. Auch wenn Gewalt sich subtil doch immer wieder einschleicht. - Es als Gewalt zu identifizieren, bleibt eine permanente Aufgabe. Denn ein Wort will wirken - und dabei kann es gewaltsam werden (manchmal ohne es zu wissen und zu wollen). Ein schlichtes Beispiel dafür sind Deutungen: Sie wirken so frei und offen, möglichst auch gut und treffend - aber wann wird eine Deutung gewaltsam? Wann tut sie dem Text oder dem anderen Gewalt an? Wäre das so klar, gäbe es hier nicht die Probleme, die wir in Kirche wie Universität immer wieder haben.

Gewalt zwingt den anderen wider seinen Willen, und sei es ein vermeintlich zzwangloser Zwang`. Gewalt verlässt sich nicht auf Anerkennung und Zustimmung, nicht auf das freie Spiel des Gesprächs, sondern sie ist kompromisslos, rigoros und (angeblich) salternativlos‘. Das mag es in der Politik geben, auch im universitären Alltagsleben, zumal wenn es pathologisch wird. Aber Gewalt provoziert Widerstand. Daher ist auch ein Wort, das sich gewaltsam aufführt und Gehorsam erzwingen will, nicht `wahrhaft, würdig und recht`. Gäbe es ein Wort Gottes, das nackten Gehorsam fordert und kein Widerstandsrecht einräumt, wäre es gewaltsam - und daher nicht Gottes Wort. Manche träumten einst von einem Wort Gottes, das wie ein Hammer Felsen zerschlage. Manche träumen noch heute, selbst in der Theologie davon, mit dem Hammer theologisieren zu können. Gewaltfantasien sind offenbar immer wieder faszinierend.

Ein Grund für solche Eskalationen scheint mir ein tiefsitzendes Begehren zu sein: Wer mehr als Wort will, sucht Ermächtigungen, um sein Wort auch durchzusetzen. Er beruft sich auf ein Amt, um sein Wort durchzusetzen; oder auf die Institution, um im Namen derselben sprechen zu können, oder auch auf Gott, um in seinem Namen die eigenen Worte durchzusetzen. Protestantisch sollte das stets Zweifel wecken, radikale Skepsis: Wer sich auf Autoritäten beruft, ermächtigt sich und sein Wort. Er verlässt sich nicht mehr auf das nackte bloße Wort, sondern will mehr: gesicherte Ermächtigung, kraft der sein Wort gelte und niemand soll ihm widerstehen können. Wort statt Gewalt ist eine gute und nützliche Regel, der man folgen sollte, in Wissenschaft wie Kirchen

mentorum, remittere peccata, reiicere doctrinam ab evangelio dissentientem et impios, quorum nota est impietas, excludere a communione ecclesiae, sine vi humana, sed verbo. Vgl. Hermann Diem, Sine vi sed verbo. Aufsätze, Vorträge, Voten, herausgegeben von Uvo Andreas Wolf, München 1965, 73-89. 
zumal. Aber Wort statt Macht - das wäre ein Irrtum, eine Selbsttäuschung. Denn wer immer etwas sagt, ist hoffentlich nicht gewaltsam, aber er ist immer schon in Macht verstrickt. Wer spricht, will wirken.

Meine Vermutung ist, Wortmacht zu beanspruchen und sich auf sie zu verlassen, ist unvermeidlich. Aber wem das nicht genügt, der wird zum Machtwort Zuflucht nehmen (selbst Paulus, wie mir scheint). Und wer mehr als Wortmacht will, Machtwort und ultimative Ermächtigung, der neigt zu Ermächtigungsfantasien - und wenn alles nicht reicht auch zur Gewalt. Wer allerdings die Unvermeidlichkeit des Anspruchs auf Wortmacht verkennt, also dass jedes Wort in Macht verstrickt ist, oder dass das Wort als Wort bereits Machtmedium ist, der verkennt die Komplikationen der Macht, genauer gesagt: der Deutungsmacht. Und er wird dann um so leichter den Eskalationen im Machtwort erliegen.

\section{Solo Verbo}

Es ist eine einigermaßen erstaunliche Denkgewohnheit, dem nackten und bloßen Wort Macht und Wirkung zuzutrauen, sich darauf zu verlassen, darauf zu vertrauen, solo verbo zu glauben, zu hoffen und zu lieben, solo verbo zu verkündigen, zu beten, zu singen - und auch in der Theologie solo verbo zu argumentieren. Solo verbo ist dabei allerdings mehrdeutig: Es meint vor allem >offenbar` Gottes Wort, daher auch Christus als das Wort in Person, und nicht zuletzt das Wort vom Kreuz als Grundwort der paulinischen Theologie - und so weiter. Wenn das nicht nur eine versehentliche Mehrdeutigkeit >des Wortes` ist, wird darin eine Kontinuität unterstellt. Und diese Kontinuität sucht die Theologie, auf dass ihr Wort am Wort Gottes irgendwie Anteil gewinnt, so dass auch für sie gelte: Im Anfang war das Wort - und zwar in jedem Augenblick des Anfangs, wenn jemand das Wort ergreift, den Mund öffnet und etwas zu sagen wagt. Die große Kette des Wortes führt vom Anfang der Welt über Inkarnation, Kreuz und Auferweckung, über Pfingsten bis zum hic et nunc.

Kann man sich damit beruhigen, es gehe doch sallein um Gottes Wort ‘? Das Christentum lebe doch im und vom Gottvertrauen, nicht vom Wortvertrauen? Ich vermute, beides gilt. Und daher wird auch die >Macht des Wortes` doppeldeutbar. Um ein Missverständnis zu vermeiden: Mit Macht ist hier nichts Übles im Sinn, nicht einfach die >Fürsten dieser Welt`. Macht ist zunächst ein Vermögen zur Verwirklichung von Möglichkeiten (ob personal oder impersonal, etwa institutionell). Und mehr noch: Sie ist auch wirksam in der Ermöglichung: wenn bisher Unmögliches möglich (gemacht) wird. Macht ist im Spiel, wenn die Grenzen von wirklich und möglich verschoben werden und die von möglich und unmöglich. Daher ist es eine ungeheure Machtformel zu sagen: Bei Gott sei kein Ding unmöglich, oder alle Dinge seien möglich dem, der da glaubt. ${ }^{2}$ Schon so etwas zu sagen, ist eigentlich unmöglich. Und es wird

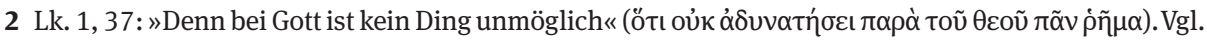
Mk. 10, 27: »Jesus aber sah sie an und sprach: Bei den Menschen ist's unmöglich, aber nicht bei Gott; 
wirklich gesagt - und auch geglaubt? Sind solche Sätze wirkliche Unmöglichkeiten oder unmögliche Wirklichkeiten? Es sind jedenfalls auch Ermächtigungsformeln: die Gott oder dem Glaubenden eine Macht zuschreiben, von der keineswegs klar ist, dass solche Ansprüche auch anerkannt werden.

Denn Macht ist stets eine Relation: zwischen sie Ausübenden und sie Anerkennenden. Macht lebt von Anerkennung. Die Macht Gottes wie die des Wortes zehren daher von der Anerkennung oder dem Vertrauen in sie. Dabei ist Macht nie simmediat‘, sondern stets medial verfasst. Wo Macht im Spiel ist, wird gedeutet, so oder so. Und umgekehrt: Wo gedeutet wird, ist stets auch Macht im Spiel, und sei es nur der Anspruch auf Aufmerksamkeit, dem Gesagten zuzuhören.

Die Kontinuität >des` Wortes - von Gott über Christus bis zum hic et nunc - dient nicht zuletzt der Ermächtigung oder Autorisierung: `Das Wort` wird aufgerufen als Grund der Deutungsmacht. Und das Wort Gottes wird aufgerufen, um sim Namen Gottes` zu sprechen. Wer wahrhaft, würdig und recht im Namen Gottes zu sprechen wagt, stellt sich in diese Kontinuität, nimmt sie als Autorisierung in Anspruch, um das Sagen zu haben (Paulus zum Beispiel). Nur - wer spricht dann? Soll doch der sprechen, der zur Sprache gebracht wird (Gott etwa) - der aber nur mit geliehener Stimme sprechen kann, der Stimme, die ihm geliehen, gegeben, übereignet wird von dem, der in seinem Namen zu sprechen wagt. Ohne solch ein absurd scheinendes Wagnis gäbe es kein verbum praesens. Das Wort, auf das swir uns gründen und berufen, kann nur laut werden, vernehmbar, wenn wir ihm unsere Stimme leihen, unsere Worte als seine ausgeben: ihm unsere Worte leihen, übergeben - oder gelegentlich auch unterschieben. Gewettet - oder vertraut - wird hier auf einen fröhlichen Wechsel: dass Gott die ihm geliehenen Worte als ihm gemäß anerkennt, ${ }^{3}$ und dass die Adressaten dieser Worte die Anerkennung teilen. Damit wird sins Offene`, gänzlich ungesichert gesprochen - wie wenn Gott den Sünder gerecht spricht. Ob das Anerkennung findet, ist durch nichts zu sichern.

Die große Kette des Logos bringt Unterscheidungsprobleme mit sich. Wäre dem nicht so, brauchte es keine Theologie. Aber unterscheiden kann man Wort von Wort, Wortmacht von Machtwort, immer wieder nur mit Worten. Das Wort Gottes ist Wort, was auch sonst.

Das Christentum ist - so gesehen - eine durch und durch rhetorische Religion, weil es sich allein auf's Wort verlassen kann - und darin nicht auf einen nackten Gott oder bloßen Christus allein, sondern auf deren mediale Präsenz im Wort, das einer in seinem Namen zu sprechen wagt. Das Christentum kann nicht anders, als sich auf die Deutungsmacht von Worten zu verlassen. ${ }^{4}$ Deswegen sollte nicht übersehen werden, dass von Schrift über Bekenntnis bis zu Verkündigung und Sakrament permanent der

denn alle Dinge sind möglich bei Gott.«; vgl. Mk. 9, 23 »esus aber sprach zu ihm: Du sagst: Wenn du

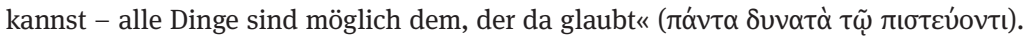

3 Damit befindet man sich in einer recht unkomfortablen Lage, weil man seine Worte so wählen muss, dass sie >Gott gefallen können sollten.

4 Auch wenn Bilder und das Zeigen im Unterschied zum Sagen eine eigene Forschungsfrage wären. 
Wortmacht vertraut wird, der Deutungsmacht des Wortes, also diesem Medium. Auf Wortmacht zu vertrauen, kann man auch >Wortglaube glaube, auch nicht reiner Geistglaube, sondern ein Glaube an das gesprochene Wort (um von Bild, Gesten, Szenen, Körpern und Verkörperung hier zu schweigen).

Im Anfang war das Wort, und das Wort ward Fleisch und ward Wort vom Kreuz und Verkündigung und Theologie - in summa also Rhetorik. >Arbeit am Wort ‘ mit Worten, in der Hoffnung, dass sein Wort darin an der Arbeit sei. Nur - wie wird ein Wort sein Wort? Jedenfalls nicht dadurch, dass man verkennt oder verleugnet, dass es immer nur als ein Wort laut wird, also als mein oder dein Wort vernehmbar.

Theologie seit Paulus und Jesus formiert sich daher a limine im Medium der Weisheit dieser Welt, genauer: der Wortweisheit namens Rhetorik. Auch die Worte Jesu waren durch und durch rhetorisch geformt, oder wem das lieber ist: narrativisch, exemplarisch in den Gleichnissen. Jesus als Rhetoriker, wäre aber ein anderes Thema. Der Glaube an das Wort vertraut auf dessen Deutungsmacht, so war die Eingangsthese. Deutungsmacht heißt die dem Sagen und Zeigen eigene Macht (potentia), die Wortmacht (nicht primär das Machtwort), die Bildmacht (nicht primär das Machtbild). Das heißt, im Sagen und Zeigen etwas hören und sehen lassen, und zwar so sehen lassen, wie gesagt, auf dass die Adressaten es auch so sehen. Das zielt im Grenzwert darauf, sie auch so sehen zu machen (etwa Christus als Gekreuzigten sehen zu machen), bis dahin, die Hörer auch so handeln, fühlen, denken und leben zu machen. Die abgründige Frage ist dann, ob die Deutungsmacht des Wortes soweit gehen kann, auch glauben zu lassen, gar Glauben zu machen?

Selbst Gott konnte oder wollte offenbar nicht anders, so die Welt durch sein Wort erschaffen wurde, sein Wille im Wort des Gesetzes offenbart wird, sein Wort Fleisch wurde und wir solo verbo gerechtfertigt werden. Das Wort Gottes darf, ja soll Glauben machen, uns zu Gläubigen machen, zu Gerechtfertigten (forensisch und effektiv). Dann kann man schwer umgehen, dem nackten Wort solche Wortmacht zuzusprechen: an die Deutungsmacht des Wortes zu glauben.

Wirksam werden soll mit der Deutungsmacht des Wortes vermeintlich allein das Wort Gottes, im Grunde also die Macht Gottes - die es aber ohne die Macht des Wortes gar nicht gäbe, die also ohne die ihm geliehenen Worte gar nicht wirksam werden könnte. Hermeneutisch wurde dieses Problem für gewöhnlich latent gehalten (und invisibilisiert): der tiefe Glaube an die Deutungsmacht des Wortes, der unvermeidlichen Verflechtung von Deutung und Macht. Wie es Macht nicht immediat gibt, so auch Gott nicht, sonst wäre er handlungsunfähig, sprachlos oder unwirksam. Folglich können weder Gott noch Kreuz noch Paulus auf das Wort verzichten - mit der Folge, dass sie sich auf die Macht des Wortes verlassen müssen.

Das wirft die sonderbare Frage auf, wer oder was ermächtigt `das Wort`, erst recht: das Wort Gottes? Die klassische Antwort ist ursprungslogisch: Es wird ermächtigt durch seinen Urheber, Gott, daher dann auch durch den König, Papst, Präsident und Prediger. Die Wette auf das Wort lautet dann, das Wort ward Geist und Fleisch, Christus also, und sein Charisma ward mit der Zeit Amt - das Wort und Sakrament verwaltet: das verbum efficax ist ein verwaltetes Wort. Sonst bräuchte es kein Amt. >Eigentlich aber, 
so die beruhigende Überzeugung, sei es stets und nur der Ursprung, der Urheber, dessen Macht im Wort wirksam werde, wenn denn nur die Kontinuität dieser Kette nicht unterbrochen werde (sei es römisch qua historischer Sukzession des Amtes oder protestantisch kraft der Kontinuität rechter Lehre und Verkündigung). Analog zum Ursprung kann man auch Institution wie Amt aufrufen: Das Wort werde ermächtigt durch das Amt (Moses, der Propheten oder Christi dreifaches Amt etwa), oder es werde ermächtigt durch die Institution, die es recht verwaltet. Dann aber wäre das Wort mächtig allein durch eine vorgängige Macht: von Institution und Amt. Es ginge im Grunde stets um Machtworte - statt um Wortmacht.

Auf Machtworte zu setzen, ist eine nicht sehr belastbare Beruhigung - weder römisch noch protestantisch. Unterstellt es doch, im Grunde sei alles in Ordnung, und wer sich an diese Ordnung hält, sei auch sin Ordnung «. Wer rite ordinatus rede, rede recht und wahr. Als könnte die >Ordnung`, die ordinatio, sichern, dass das Wort auch wahrhaft, würdig und recht sei. Das ist so gängig und gern geglaubt, wie doch auch nur eine Ableitung und Verschiebung: die Ermächtigung durch die Ordnung, eine anonymisierte Größe, die wie ein Kraftfeld wirke: sei es die Institution, die Lehrtradition, das Dispositiv oder was auch immer. Wem das als Legitimation reicht, mag sich damit beruhigen - und damit auf die Legitimität und Macht einer Ordnung vertrauen (und ihr glauben). Institutionenglaube - statt Wortglaube hieße das. Protestantisch scheint mir das nicht empfehlenswert.

Je genauer man fragt, desto klarer und klärungsbedürftiger wird die Macht des Wortes (wie der übrigen Medien). Beunruhigend daran sollte sein, dass in der von Gott geliehenen (ihm zugeschriebenen) Wortmacht stets zugleich die dem Wort wie der Sprache eigene Macht am Werk ist und sein muss. Gott ohne unsere Worte bliebe stumm, ein verborgener Gott. Aber ihm die eigenen Worte leihen, ist eine prekäre, riskante, gefährliche Aufgabe: ihm geben, zuschreiben, was doch nur selbst gesagt sein kann, von jedem selbst, der das Wort zu ergreifen sich traut. Zugespitzt gefragt: Ist der Glaube an Gott stets ein Glaube an das Wort und die Wortmacht? Zehrt die gern aufgerufene Macht Gottes (und sei es die Macht seiner Liebe) im Grunde die Macht des Wortes - der ihm geliehenen Worte? Zumindest den Deutungsmachtanspruch der eigenen Worte kann keiner vermeiden, der spricht, erst recht, wenn er von oder über Gott spricht.

Dass `Gott ‘ und `Wort` stets einträchtig zusammenwirken, ist keineswegs sicher, wie der Gebrauch des >Wortes Gottes` zeigt. Zur Eigendynamik des Mediums namens Wort gehört sein Wie, in aller Verfügbarkeit (Rhetorik, Performanz, Inszenierung) und Unverfügbarkeit (Kontingenz, Deutung der Anderen, andere Deutungen). So wird das >Wort Gottes`, auf das die Einen als charismatische Wortmacht rekurrieren, von Anderen nur als geistloses `Machtwort aufgefasst und entsprechend kritisiert. Die Medialität des Wortes wirkt mit, in allen Rückkoppelungen und Verstärkereffekten, sei es die Wörtlichkeit des Wortes oder seine Mehr-als-Wörtlichkeit, seine Metaphorik, Stimmlichkeit, Gestik oder in summa seine Leibhaftigkeit und Eigendynamik. Dabei treten zum Wort auch andere Medien mit ihrer Deutungsmacht hinzu: Bild, Ton, Körper, Raum und Atmosphäre. Theologisch sind solche Erweiterungen nur zu passend. Denn >Gott spricht nicht nur, er 
zeigt sich auch.${ }^{5}$ Oder analog formuliert: Der Glaube kommt nicht nur aus dem Hören, und er spricht nicht nur, sondern zeigt sich auch. Im Konflikt jedenfalls, im Deutungsmachtkonflikt, hilft der Rekurs auf die große Kette des Logos von Gott zum aktuellen Wort hin kaum. Denn dieser Rekurs steht jedem frei, wohl oder übel. Daher bleibt nur, sich auf die Wortmacht zu verlassen, statt ein institutionelles oder gar göttliches Machtwort zu erheben. Wer `Zeichen und Wunder` erwartet, wird enttäuscht werden und sola verba finden oder anders: ecce verbum.

Wer hier nachfragt und unterscheidet (Wortmacht von Machtwort), der stiftet Fraglichkeit über das tragende Grundvertrauen: in Gottes Wort als Wort. Eine Hermeneutik der Rhetorik kann daher die rhetorische Gestalt der Wortmacht nicht latent lassen, sondern macht manifest und explizit, was sonst verborgen wird. Das Medium Rhetorik muss seine eigene Medialität invisibilisieren, um nicht zu kollabieren. Hier wird Hermeneutik kritisch: Sie lässt labil werden, was ansonsten stabil wäre. Das ist nicht mit einer Hermeneutik des Verdachts zu verwechseln, als wäre Rhetorik per se eine unanständige Angelegenheit. Solche Fehlschlüsse sind sowohl von der Aufklärung als auch von der dialektischen Theologie kolportiert worden - und erstaunlicherweise sind sich im Verdacht gegen die Rhetorik Kulturprotestanten wie dialektische Theologen und manche Lutheraner frappierend einig. Wer sich von Rhetorik (mit Rhetorik) distanziert, kann sie getrost unter Generalverdacht stellen. Exegetisch allerdings und kirchengeschichtlich, praktisch-theologisch oder pädagogisch wird dieses Missverständnis kaum noch geteilt. Es scheint eine Vorliebe der Systematik zu sein, daran festzuhalten.

Ein Grund dafür könnte sein, dass das Vorurteil herrscht, wer Rhetorik sage, entsorge die Wahrheitsfrage - als würde man damit einem (halb verstandenen) Nietzsche folgen, oder endlich die Sophistik triumphieren lassen, am Ende gar deren Wiedergänger, die Dekonstruktion. Res, non verba! ist der eine Schlachtruf, die `Macht der Wahrheit oder >der Liebe der andere, statt bloßer Wortmacht, die unter Rhetorikverdacht steht. Die schlichte Antwort darauf wäre: Was Sache ist, sagen die Worte, also die Rhetorik. Daher ist es unvermeidlich, sich auf die Macht der Worte zu verlassen.

Eberhard Jüngel erklärte: „Der gnädige und als solcher den gottlosen Menschen rechtfertigende Gott ist ein redender Gott. $\aleph^{6}$ Die Metapher im Hintergrund ist unüberhörbar: Gott als Rhetor - so wie in Jesu Worten das Reich Gottes realpräsent wird, oder im Wort vom Kreuz Christus gegenwärtig vor Augen treten möge, oder im forensischen Wort der Rechtfertigung der Sünder gerecht gesprochen und gemacht wird. Die Begründung dieser These ist bei Jüngel erstaunlich profan: "Sprache ist die ursprüngliche Einheit von Sinnlichkeit und Geist « ${ }^{7}$. Dann wäre Gott ein Rhetor, weil sein

5 Vgl. Philipp Stoellger, Fundamentaltheologie zwischen Lexis und Deixis. Sagen und Zeigen als Leitdifferenz theologischer Reflexion, in: Christoph Böttigheimer / Florian Bruckmann (Hg.), Glaubensverantwortung im Horizont der »Zeichen der Zeit«, Freiburg 2012, 329-373.

6 Eberhard Jüngel, Das Evangelium von der Rechtfertigung des Gottlosen als Zentrum des christlichen Glaubens, Tübingen 1999, 169.

7 Jüngel, Das Evangelium von der Rechtfertigung, 173. 
Geist nicht ohne den sinnlichen Leib des Wortes sein kann? Weil der Geist nicht wäre, wäre er nicht sinnlich? Wäre dann die Macht Gottes ursprünglich die Macht des sinnlichen Wortes? Gott ward Wort, weil Gott sonst nicht Gott sein könnte? Weil er Wort sein muss, um überhaupt wahrnehmbar, wirksam und mächtig sein zu können unter uns? Wäre ein wortloser Gott nicht Gott - und ein gottloses Wort nicht Wort? Gott und Wort werden beunruhigend ununterscheidbar.

Jedenfalls wird mehrdeutig und klärungsbedürftig, was für eine Macht hier am Werk ist. Die erste Antwort war: Deutungsmacht, also ein Chiasmus, eine Kreuzung und Verflechtung von Wort und Macht. Aber wessen Deutungsmacht ist hier am Werk? Das `Wort allein`, also die Macht dieses Mediums? Wenn das schon für Gott und Wort fraglich ist, ob seine Macht möglicherweise geliehen ist, eine Leihnahme bei der Macht des Wortes, ist das für das Verhältnis von Kreuz und Wort nicht weniger wichtig zu fragen. War das Kreuz der Gipfel der Ohnmacht, wurde es im Wort vom Kreuz mächtig, auf dass es im Urteil, im Rechtfertigungsurteil machtvoll wirksam werde. Ist dann das apostolische Wort vom Kreuz ein Machtwort: eine Überwältigung des machtlosen Kreuzes? Oder vertraut es auf die nackte Wortmacht: auf die Macht des Wortes, uns hören, sehen und glauben zu machen? Wer hier mehr will als `bloße Worte`, will Macht, andere Macht als bloße Wortmacht. Die Macht Gottes? Des Apostels und sein Machtwort? Oder die Macht der Ordnung, der Institution? Was sub contrario (in aller Ohnmacht) offenbar wurde, würde dann sub contradictione verkehrt: in aller Macht eines Machtwortes?

Die gegenläufige Hoffnung wäre: dass im Wort vom Kreuz der Machtanspruch vergeht um des Gekreuzigten willen. Aber wer `Wort`sagt, ist bereits im Agon der Mächte verstrickt. Der Konflikt in Korinth war dessen paradigmatische Manifestation: ob das gewagte Wort vom Kreuz als Machtwort auftritt oder bloß mit Wortmacht, die genuin widerspruchsfähig, dem Einspruch exponiert bleibt: Ecce verbum. Wer diese Widerspruchsfähigkeit, diese semantische Fragilität mit Machtworten absichert, hat die Pointe bereits verspielt.

Auch bei Paulus wurde im Konflikt mit den Gegnern unüberhörbar, wie nicht allein Gott und der Gekreuzigte, sondern auch die Theologie von der Macht des Wortes lebt, mit dem latenten Hintersinn, sich dabei an die Macht des Wortes Gottes anzulehnen, wenn nicht mehr. Und das ist täuschungsanfällig. So meinte Gerhard Ebeling:

"Das Reden über Gott, von dem man um seines Gegenstandes willen ein besonderes Maß an Macht erwarten sollte, ist einerseits ungewöhnlich anfällig für eine Depravierung, die mit der Faszination des Imponierenden ausgestattet sein kann, anderseits von einer Wehrlosigkeit und Schwachheit, in der sich gerade die spezifische Macht des Redens über Gott verbirgt. Wie schwer ist es aber, sich dieser verborgenen Macht anzuvertrauen. $\ll^{8}$

Das Problem der Ermächtigung religiöser oder theologischer Deutung rim Namen Gottes` ist damit keineswegs ıgelöst‘, aber es ist gesehen und benannt (ohne damit

8 Gerhard Ebeling, Dogmatik des christlichen Glaubens, Band 1, 3. Auflage, Tübingen 1987, 163. 
gebannt zu sein). Es deutet sich ein Aspekt an, der zur christologischen Topik gehört: Die >Wehrlosigkeit und Schwachheit ist seit der paulinischen Rhetorik ein besonderer Ausweis religiöser wie theologischer Rede, mit der umgehend eine Ermächtigung sub contrario einhergehen kann.

Das Modell einer Mimesis, einer imitatio Christi ist für die christliche Rhetorik prägend gewesen (wenn auch ambivalent und daher nie ohne sic et non). Die Ermächtigung der möglichst seinfachen` Rede operiert mit dem Argument der Gleichförmigkeit mit ihrem `Gegenstand `, der in seiner Niedrigkeit entsprechend `arm ^ repräsentiert werde - und erst damit eigentlich angemessen. So gesehen wird unter dem Gewand der humilitas ein Deutungsmachtanspruch verborgen mit der These, (nur) diese Form entspreche dem Inhalt, so dass der Thematische auch in der Rede real gegenwärtig sei (im Geist). Der eigene Deutungsmachtanspruch wird delegiert (propter Christum) und sogleich aus der (selbstgemachten) Delegation abgeleitet. Eine prekäre Ambivalenz.

Selbst Ebelings Ansinnen, sich >dieser verborgenen Macht anzuvertrauen`, also der Macht Christi sub contrario des Kreuzes, scheint in diese Richtung zu weisen: dass damit dann doch die immer noch größere Macht Gottes im Spiel der Deutung sei. Die erheblich schwierigere Aufgabe wäre, sich dieser Macht nicht anzuvertrauen, um sie nicht für die eigene Rede in Anspruch zu nehmen. Das heißt: nicht die eigenen Worte als durch Gott autorisiert auszugeben und sei es noch so indirekt. Gilt es doch so deutlich wie möglich der theologischen Versuchung $\mathrm{zu}$ widerstehen, die eigene Deutung als ıvon Gott ermächtigt` auszugeben. Denn das hieße theologisches Kapital zu schlagen aus dem, der der Theologie strikt entzogen ist und bleibt. Aus Gott lässt sich nicht die Geltung der eigenen Worte ableiten. Denn die kann nur unvertretbar selber beansprucht und argumentativ eingelöst werden. Ist in Geltungsfragen doch jeder für sich selbst gefordert. ${ }^{9}$ Da kann auch ein Gott nicht helfen.

Ebeling fügte den zitierten Worten noch die Wendung an: »Damit wird der Blick auf die unerhörte Diskrepanz zwischen dem Anspruch und dem Erfolg des Redens über Gott gelenkt « ${ }^{10}$. Diese Diskrepanz gehört zu den Grunderfahrungen religiöser wie theologischer Rede: von der Macht des Wortes zu reden, maßgeblich des Wortes Gottes als Wort vom Kreuz, aber dabei weitgehend machtlos zu bleiben und im Konfliktfall doch um so mehr Macht zu beanspruchen, wie Paulus gegenüber den korinthischen Gegnern im Deutungsmachtkonflikt. Das führt in eine rhetorische Schere: bei noch so großer Ohnmacht einen immer noch größeren Machtanspruch zu stellen. Und diese Schere öffnet sich um so weiter, als für die theologische Rede die reale Gegenwart des

9 Vgl. Martin Luther: »Wir sind allesamt zu dem Tod gefordert und wird keiner für den anderen sterben, sondern ein jeder in eigener Person für sich mit dem Tode kämpfen. In die Ohren könnten wir wohl schreien, aber ein jeder muß für sich selbst geschickt sein in der Zeit des Todes. Ich werde dann nicht bei dir sein noch du bei mir« (aus dem Jahr 1522; in: WA 10, 3; 1, 7-2, 2); vgl. Gerhard Ebeling, Lutherstudien II, 3, Tübingen 1989, 463.

10 Ebeling, Dogmatik, 163. 
allmächtigen Gottes prätendiert oder insinuiert wird. Wem die labile Wortmacht nicht reicht, rekurriert auf Gottes Wortmacht - und spricht am Ende nur noch ein Machtwort.

Demgegenüber bedarf es einer Deutungsmachtkritik und einer Differenzkompetenz, die sich im eigenen Reden nicht auf die Macht Gottes beruft, sondern sich unvertretbar selber in Verantwortung sieht und exponiert. Wie schwer das im Konflikt fällt, zeigt der Deutungsmachtkonflikt in Korinth: Paulus nahm Zuflucht zum sapostolischen Amt ( auch wenn das erst später erfunden worden sein mag). Wer mehr als nackte Wortmacht sucht, wird schnell bloß Machtworte sprechen. Aber wer an die Wortmacht glaubt - glaubt nicht an Gott allein - sondern auch an die Macht eines jeden Wortes. Selbst Gott kann nicht anders, als darauf zu vertrauen. Auch Jesus vertraute der Wortmacht seiner Gleichnisse. Das Wort ward Fleisch - und wieder Wort. Ecce verbum.

\section{Der Deutungsmachtkonflikt in Korinth ${ }^{11}$}

Der 1. Korintherbrief ist das Dokument eines Deutungskonflikts, der sich als Deutungsmachtkonflikt entwickelt. Die Dimension der Macht in diesem Deutungskonflikt ist nicht allein semantisch, insbesondere theologisch-semantisch zu fassen, sondern scilicet auch bedingt dadurch, dass soziale Trägergruppen und personale Manifestationen derselben im Spiel sind. Da hier allerdings snur der Machtkonflikt auf Deutungsebene thematisch ist, bleibt der Blick darauf konzentriert. Worum genau gestritten wird - ist seinerseits eine Frage von Deutungsmachtkonflikten im exegetischen Diskurs. ${ }^{12}$ Sieht man von älteren Thesen eines Antinomismus, Judaismus, einer Gnosis oder Protognosis ab, bleibt bei allen einzelnen Themen (Abendmahl, Auferstehung, Ethik etc.) fraglich, worin die Gründe der theologischen Differenz bestehen. Hier sei davon ausgegangen, es gehe um:

- Weisheit, die offenbar in ihrer Deutung und Relevanz umstritten ist zwischen Paulus und seinen >Gegnern<, und damit um die Pneumatologie;

- Eschatologie, sofern in 1 Kor. 4, 8 ein Indiz vorliegt, dass es den Gegnern um eine realisierte oder präsente Eschatologie geht, die von Paulus kritisiert wird;

11 Wenn im Folgenden von >Paulus die Rede ist, wird eine Unterscheidung zugrunde gelegt: Erstens ist der historische Paulus, wie er von Historikern rekonstruiert werden kann, zu unterscheiden, zweitens, vom biblischen Paulus der kanonischen Texte des Neuen Testaments, und beide, drittens, vom imaginären Paulus, der in Deutungen wie im religiösen und institutionellen Gebrauch konstituiert wird: als der Heilige, als Kultfigur, Amtsperson und theologische norma normans. Paulus wird somit dreifaltig differenziert, ohne allerdings damit eine Wesenseinheit dieser drei Figuren unterstellen zu können. Damit geht es im Folgenden nicht um die Nachzeichnung eines quellensprachlichen Befundes, sondern lediglich um systematische Fragen und deren Erörterung - insbesondere um die Problematisierung der Eigendynamik des imaginären Paulus in seiner Deutungsmacht und seinem Wirkungspotential.

12 Vgl. dazu Wolfgang Schrage, Der erste Brief an die Korinther, Band 1: 1 Kor. 1, 1-6, 11, Zürich / Braunschweig 1992, 38-63. 
- $\quad$ Christologie und Soteriologie, sofern die Deutung der Auferstehung (Christi und >aller`) strittig ist;

- das Verhältnis von Kreuz und Auferstehung benennt die quaestio, die in der Wirkungsgeschichte auseinandergetreten ist.

Im Deutungsdiskurs wurde es zur Frage, ob das Kreuz oder die Auferstehung das eigentliche Heilsereignis sei, und damit auch, ob der Glaube Glaube an den Gekreuzigten sei oder an den Auferstandenen. Das ist soweit plausibel, als offenbar >das Wort vom Kreuzı zur Debatte steht und damit die Deutung des Gekreuzigten und die Deutungsmachtansprüche der Deutungen. Das steht im Licht der späteren Frage um das Verständnis von Theologie: ob sie theologia crucis oder theologia gloriae sei. Damit wird manifest, was bereits bei Paulus im Verhältnis zu seinen Gegnern strittig gewesen sein muss: der Streit um die Deutungsmacht des Wortes, hier genauer: des Apostolats als Autorisierung bzw. Ermächtigungsgrund der paulinischen Theologie.

Der Deutungsmachtanspruch der paulinischen Argumentation zielt darauf, das >Wort vom Kreuz` als Torheit im Medium der Weisheit zur Geltung zu bringen. Man kann auch sagen, es in der Rhetorik gegen die Rhetorik zur Sprache zu bringen. Das Problem des Paulus ist seit Platon vertraut: gegen die Sophisten sophistisch vorzugehen, um als der bessere Sophist den Agon zu gewinnen - im Namen der Wahrheit und Weisheit. Es geht dabei um Fragen der Deutung, nicht >nur der Auslegung (der Schrift) oder der (methodischen) Interpretation, sondern um die vorwissenschaftliche, lebensweltliche, im Grunde sapientiale Art und Weise des Sehens und Sagens quod res est, also wie der Gekreuzigte vor Augen gemalt wird, auf dass die Adressaten ihn so sehen wie gezeigt und so glauben wie gedeutet. Hier wird der Grenzwert manifest, ob die apostolische Rede ihre Hörer glauben lassen und machen kann. Eine >Theologie des Gekreuzigten « ist a limine eine Theologie, die svor Augen maltı, wenn Paulus an die Galater schreibt: ${ }^{13}$ »Welchen Christus Jhesus fur die augen gemalet war und jtzt vnter euch gecreutziget ist ${ }^{14}$.

Dann ist wenigstens andeutungsweise zu klären, in welchem Sinn hier von >Deutung zu sprechen ist: Deutung ist eine kommunikative Handlung oder Zeichenpraxis von Personen oder von Medien, Apparaten, Institutionen, Methoden, Strukturen, ursprünglich deiktisch, gestisch, mimisch, tonal, leiblich, kinästhetisch, eine Weise des Zeigens, d.h. etwas sehen lassen und machen (bzw. wahrnehmen, erkennen); in semantisch differenzierter Weise sprachlich, in ikonisch differenzierter Weise bildlich; in der Regel bewusst, meist intentional (Normalfall), ggf. aber auch unbewusst oder auch nichtintentional (Liminalfall: z. B. Symptome). Deutung dient der Lenkung der Wahrnehmung, Kinästhesie und Aufmerksamkeit ihrer Adressaten, die ihr durch Aufmerksamkeit bis zur Anerkennung (prozedural, graduell) folgen (sollen). Dadurch können die

13 »O ihr unverständigen Galater! Wer hat euch bezaubert, denen doch Jesus Christus vor die Augen gemalt war als der Gekreuzigte« (Gal. 3, 1).

14 So nach Luthers 1544/45er Übersetzung. In den Revisionen hieß es dann: Euch Christen in Galatien habe ich Christus »vor die Augen gemalt, als wäre er unter euch gekreuzigt«. 
Adressaten einer Deutung Macht verleihen (im Sinn von Folgen, Anerkennen, Einverständnis), wie zugleich das Deuten selbst bereits einen Machtanspruch auf Folgen, Schauen, Aufmerksamkeit impliziert. Damit sind zwei Seiten von Deutungsmacht benannt, eine dritte bilden Ordnungen, Dispositive oder Strukturen, die modal die ersten beiden bedingen in Eröffnung und Begrenzung oder Ermöglichung und Verunmöglichung. Gedeutet wird zum Zweck, Relevanz zu setzen bzw. Unterschiede zu machen (wie Kontrastierung), näherhin um die Bedeutung des Gedeuteten zu bestimmen, bis zur Verständigung bzw. Kommunikation über das Gedeutete.

Von >Deutung « ist hier zu sprechen, weil es im Konflikt um das >Wort vom Kreuz nicht >nur um eine methodisch disziplinierte Interpretation geht oder um zunftgemäße Schriftauslegung. >Christus vor Augen malen` oder die christologische Paradoxierung von Weisheit und Torheit ist nicht snur Schriftauslegung, methodische Interpretation oder Exegese, sondern eine rhetorische Praxis mit aller enargeia und energeia: Es ist ein Sagen und Zeigen, ein zeigendes Sagen und sagendes Zeigen, das sich nicht auf Gesagtes und dessen methodische Interpretation zurückziehen kann. In solchem Sagen wie Zeigen wird Singuläres und infinit Komplexes in die symbolische Form der Prägnanz gebracht: `Christ ist erstanden` wie >das Wort vom Kreuz`. Nur sind diese Prägnanzen im Streit mit den Gegnern nicht mehr irenische Konsens-, sondern polemische Konfliktformeln. Wären sie unstrittig, wären diese Prägnanzen Topoi als gemeinsame Gesichtspunkte, von denen aus Konsens zu finden wäre. Aber erst einmal selber zum Konfliktgegenstand geworden, ändern sie ihren Status und werden zu Kampfplätzen, auf denen der Deutungsmachtkonflikt um Christus, Glaube, Kreuz und Apostolat ausgetragen werden.

In diesem Konflikt wird mit Machtanspruch das Wort vom Kreuz zur Geltung gebracht, also der Gekreuzigte in einen Machtkonflikt verstrickt - bei dem das rechte oder wahre Wort vom Kreuz gegen eine andere Christologie ins Feld geführt wird (so zumindest die paulinische Konstruktion, nach der den Gegnern eine Christologie zugeschrieben wird, nach der die Herrlichkeit der Auferstehung das eigentliche Heilsereignis sei ${ }^{15}$ ). Performativer Sinn und Zweck solch gewagter Konfliktrede ist es, zu sagen und zu zeigen, was man wie sieht und wie man es recht sehen soll. Also in diesem Fall: die Hörer Christus als Gekreuzigten sehen zu lassen; sie ihn so sehen zu lassen, wie Paulus ihn zeigt; sie so sehen zu machen - bis dahin, sie auch glauben zu lassen und glauben zu machen, dass alles Heil allein im Gekreuzigten zu finden sei. Rhetorisch heißt das Persuasionstechnik. Etwas weiter gefasst, geht es darum, etwas als etwas zu deuten, auf dass die Hörer dieser Deutung folgen, sie teilen und weitergeben. Im maximalen Grenzwert heißt das: dass sie im Lichte dieser Deutung alles andere deuten, Gott, Selbst, Welt und Leben.

Im Streit mit Korinth geht es daher sum’s Ganze`: um die Deutung Christi als des Gekreuzigten, um das Kreuz als Weisheit Gottes - und damit um den Meister der

15 Vgl. dagegen Hansjürgen Verweyen, Gottes letztes Wort. Grundriß der Fundamentaltheologie, 3. Auflage, Regensburg 2000, $338 \mathrm{ff}$. 
Deutung dieser >Meisterdeutung، als Deutung aller Deutung, kraft derer erst die Erfahrung mit aller Erfahrung 'gemacht ` wird. Paulus’ Anspruch geht auf nicht weniger als die maßgebende Meisterdeutung - mit entsprechendem Willen zur Deutungsmacht: der Deutungskonflikt um das Wort vom Kreuz, so dass ein Machtkonflikt über Deutung ausgetragen wird, manifest als Deutungsmachtkonflikt mit den Andersdeutenden. Der apostolische Anspruch geht darauf, dass darin sim Grunde` der Gedeutete selber deute: weil Christus sich als Gekreuzigter offenbart habe, die Weisheit Gottes also im Kreuz offenbar sei. Die apostolische Rhetorik aber kann nicht anders, als selber so zu deuten, dass der Gekreuzigte sich selber deute; selber ihn so zu zeigen und sehen zu lassen, auf dass Christus als Gekreuzigter geglaubt werde. Das ist die tiefe Paradoxie der Meisterdeutung, die diesen Deutungskonflikt zu meistern sucht.

Dabei entwickelt Paulus ein >kanonisch`gewordenes Deutungsmachttheorem: Er operiert mit der großen Kette des Logos, in der die Kontinuität zur Macht Gottes als Ursprung und Autorisierung der eigenen Deutungsmacht in Anspruch genommen wird mit einer gleichzeitigen Invisibilisierung der eigenen Macht(-ansprüche), um die Machtfrage nicht selbst zu entscheiden, sondern, so die Prätention, von Gott entscheiden zu lassen, der schon entschieden habe. ${ }^{16}$ Daher ist nur zu verständlich, wenn es 2 Kor. 11a heißt: »Ich bin ein Narr geworden! Dazu habt ihr mich gezwungen.« Das Wort des Paulus beansprucht die Vollmacht des apostolischen Amtes, in christomorpher Mimesis, aus dem Wort vom Kreuz und letztlich aus dem Wort Gottes selbst. Das Apostolat fungiert daher als Ermächtigung - wider Willen - durch Gott selbst, so dass der Apostel der allein legitime Deuter (Redner, Verkündiger) ist als Gottes Delegierter. Im Wort vom Kreuz deute Gott selbst das Kreuz - so dass hier kein Widerspruch mehr möglich sei. Wer dieser >Torheit des Unmöglichen`(folie de l'impossible) noch widerspräche, könnte nur in der Hölle landen: in der definitiven Exklusion.

Das Problem ist, dass auch Paulus solo verbo, allein mit dem Wort deuten kann. Zwischen Gottes Macht im Ursprung und dem Machtanspruch im Machtwort des Apostels spielt daher als Figur des Dritten die Wortmacht, also die dem Wort eigene Dynamik - auf deren Vermittlungs- und Überzeugungskraft letztlich gewettet wird: auf die Deutungsmacht des Wortes. Die für jede Theologie kritische Frage ist daher, ob man es bei dieser Schwachheit der Wortmacht belässt oder mehr beansprucht, um dieselbe nochmals abzusichern, sei es mit Machtworten oder der Ursprungsmacht als Rekursgrund (mit vermeintlich deutungsfreier Letztbegründung)?

Für die hermeneutische Perspektive auf diesen Deutungsmachtkonflikt sind die exegetischen wie die dogmatischen Analysen der Semantik und Philologie so hilfreich - wie sie zugleich den Invisibilisierungen und Paradoxien folgen, die der paulinische Text vorgibt. Sein Deutungsmachtanspruch und damit sein Konnex von Macht und Semantik operiert in einer klärungsbedürftigen Struktur, die in diversen Paradoxie-

16 Vgl. aber 1 Kor. 7, 40: „Seliger ist sie aber, nach meiner Meinung, wenn sie ledig bleibt. Ich meine aber: ich habe auch den Geist Gottes.«; 1 Kor. 10, 15: »Ich rede doch zu verständigen Menschen; beurteilt ihr, was ich sage. « und 1 Kor. 11, 13: »Urteilt bei euch selbst, ob es sich ziemt, dass eine Frau unbedeckt vor Gott betet.« 
rungen manifest wird. Die Struktur der paulinischen Argumentation ist eine Umwertung aller Werte - mit einem ganz erheblichen `Willen zu Macht`. (Damit wird merklich, dass Nietzsche sich im Grunde mit Paulus misst, wenn es um Gott geht - und zugleich um die Wortmacht, derer sich Nietzsche so virtuos zu bedienen weiß.)

Die Paradoxien, mit denen Paulus operiert, sind:

- mit Macht das Andere der Macht zur Geltung und Anerkennung bringen bzw. die Ohnmacht im Medium der Macht;

- mit dem Supplement des Kreuzes, dem `Wort vom Kreuz die Ohnmacht Christi als höchste Macht zur Sprache zu bringen und prekär analog die Ohnmacht des Apostels als den Gegnern überlegene Macht;

- mit Rhetorik das Andere der Rhetorik zur Sprache zu bringen, bzw. in Deutung das Anderen der Deutung als snicht nur Deutung، zur Geltung zu bringen;

- mit Weisheit die Torheit zu vertreten, um mit dieser Torheit die Weisheit zu widerlegen.

Die Paradoxie dreht sich um die Frage: Wie kann die Torheit des Kreuzes im Medium der Weisheit dieser Welt zur Sprache gebracht werden? Oder: Wie kann im Medium des griechischen Logos das christliche Pathos zu Wort kommen? Ohne die Lizenz zur Torheit (genus humilis) eskalieren zu lassen? Ohne sie (mit Überbietungsgestus) als die höhere Weisheit schlicht zu behaupten. Ohne sie argumentationsfrei zu bezeugen, auf dass nur der Glaube an den Zeugen möglich bliebe. Ohne die Umbesetzung zur Gegenbesetzung zu stilisieren, mit Dualisierung und Exklusion. Ohne mit einem Machtanspruch aufzutreten, der das Machtwort an Stelle der Wortmacht setzt? Und zwar so, dass im Medium des Anderen das keineswegs Eigene als das Andere Aller zur Sprache kommt? Man kann den Eindruck gewinnen, Paulus taumele hin und her zwischen Machtwort und Wortmacht - mit der immer wiederkehrenden Versuchung, letztlich doch auf ein Machtwort zu rekurrieren, statt sich auf die schwache Wortmacht zu verlassen - auch wenn er weiß, dass das ınärrisch` wäre.

\section{Wortmacht versus Machtwort des Paulus}

Die Macht des Wortes heißt, dass es sehen lässt und sehen macht, dass es ordnet, orientiert und aufklärt, dass es Horizonte eröffnet, neue Wirklichkeiten, Möglichkeiten und gelegentlich sogar Unmögliches wirklich werden lässt, dass es bewegt in Affekt wie Motivation, bekehrt in Buße, befreit im Zuspruch, in Anspruch nimmt, Frieden stiftet, und im Anfang vor allem frei oder gerecht spricht, als wäre das Wort nicht nur der Güter Gefährlichstes, sondern vor allem deren Mächtigstes. Ein Wort kann sehen lassen, etwas so sehen lassen, die Adressaten es so sehen machen - auf dass es sie glauben macht. Das ist die Deutungsmacht des Wortes: etwas so zu sagen, um es so zu zeigen und uns damit so sehen lassen und glauben machen. Auch wenn es hyperbolisch klingt - genau darauf scheint Paulus zu zielen: dass die Hörer nicht nur an Christus glauben, sondern so glauben, wie er, und dazu muss er sie so glauben lassen 
und machen, wie er Christus deutet - mit dem Anspruch, das sei Gottes Deutung (die ihm erschlossen wurde in Analogie der Propheten).

Die Entfaltung dessen findet sich in der rhetorischen Tradition der evidentia, wie Cicero die aristotelische energeia übersetzte, und der benachbarten enargeia (die von Horst Bredekamp Aristoteles zugeschrieben und als Grundfigur der Bildtheorie verwendet wird) ${ }^{17}$ Die Bildkraft als dynamis wird von ihm mit der enargeia verbunden, die Aristoteles in der Poetik aus dem lebendigen >Vor-Augen-Führen werde in der Rhetorik als >Wirksamkeit begriffen. ${ }^{18}$ Pseudo-Longinus sprach der rhetorischen Fantasie die enargeia zwar als Deutlichkeit zu, ${ }^{19}$ zugleich aber sei sie auch Bilderzeugung: eidolopoiia. ${ }^{20}$ Das ist es, was die religiöse Rhetorik leistet, wenn sie gelingt: Eidolopoiie - möglichst ohne Eidolatrie, so der stets wiederkehrende kritische Vorbehalt. Das Vor-Augen-Führen ist ein Vor-Augen-Malen, ein Zeigen im Sagen, kraft der Lebendigkeit des Wortes, ${ }^{21}$ etwa narrativen wie metaphorischen Sagens. ${ }^{22}$ Eben diese Lebendigkeit, die Wortmacht, kann als Verlebendigung wirken, die an die (angeblich) magische Animation grenzt: als würden die Adressaten bezaubert, wenn nicht verhext. Aber das >Vor-Augen-Führen « wie >-Malen` ist eine funktionale Bestimmung, im Sagen zu Zeigen. Es bezeichnet das Deiktische der Lexis, die Bildlichkeit am Ort der Sprache kraft der Imagination.

Ansgar Kemmann erklärte zur Evidenz, dass sie in zwei verschiedenen Sprachauffassungen auftreten kann: »im Falle der enérgeia das ontologisch-dynamische Sprachverständnis des Aristoteles, im Falle der enárgeia eine repräsentationslogischestatische Sprachauffassung, wie sie für die römisch-hellenistische Rhetorik kennzeichnend war « ${ }^{23}$. Daher wäre für Aristoteles wie für die Frage nach der Evidenz enargeia unpassend, sondern energeia zu sagen. Da mit energeia vor allem die Wirksamkeit und Kraft benannt wird, kann die enargeia für die Klarheit und Deutlichkeit bis zur Lebendigkeit des Vor-Augen-Malens gelten.

Sehen lassen und machen heißt: das Gezeigte >zurechtmachen`, zu dem machen, als was es gezeigt wird: den Gekreuzigten ızurechtmachen`, den Jesus zum Christus,

17 Vgl. Horst Bredekamp, Theorie des Bildakts. Frankfurter Adorno-Vorlesungen 2007, Berlin 2010, 20.

18 Vgl. Bredekamp, Theorie des Bildakts, 22.

19 Vgl. [Pseudo-]Longinus, Vom Erhabenen, herausgegeben und übersetzt von Otto Schönberger, Stuttgart 2008, 15, 2.

20 Vgl. [Pseudo-]Longinus, Vom Erhabenen 15, 1.

21 Dabei ist das `Lebendige « nicht als poetisch, kreativ oder schlechthin neu zu überhöhen. Die feinen Unterschiede und Varianten, die innovativen Differenzen in der Wiederholung lassen auch die topische Metaphorik durchaus lebendig bleiben. Es ist eine schlechte Übertreibung, die Tropen in lebendig und tot zu zerlegen. Ist doch ihr Leben zwischen diesen Extremen das, worin und wovon jede Rede und Erzählung lebt.

22 Wobei die Metapher hier zur Synekdoche der ihr verwandten Tropen und Figuren dient.

23 Ansgar Kemmann, Evidentia, Evidenz, in: Historisches Wörterbuch der Rhetorik 3 (1996) 33-47; hier: 40; vgl. dens. / Daniel Gross (Hg.), Heidegger and Rhetoric, New York 2006, sowie darin: Daniel Gross, Introduction. Being-moved - The Pathos of Heidegger’s Rhetorical Ontology, $1 \mathrm{ff}$. 
das Kreuz zum Wort vom Kreuz, die Torheit zur Weisheit etc. Das weckt den religionskritischen Impuls und ebenso den rhetorikkritischen. Wieder wäre das ein Kurzschluss. Denn ihn so >zurechtzumachen` heißt, den Hörern ihn so vor Augen zu führen, dass sie ihn auch so sehen, hören, vorstellen - und glauben. In Rede und imaginativem Hören wird diese Möglichkeit wirklich - so lautet die Wette auf die Deutungsmacht der Rhetorik, auf ihre Macht in der Schwachheit des Wortes: auf ihre Offenbarungspotenz, Jesus als Christus erscheinen zu lassen, das Kreuz im Wort vom Kreuz im Hören zum Glauben weckenden Heilsereignis werden $\mathrm{zu}$ lassen, also um die Hörer glauben zu machen, mitleiden, mitsterben und mitauferstehen $\mathrm{zu}$ lassen und sie $\mathrm{zu}>$ Augenzeugen` zu machen, die das Gesehene weitergeben.

Das Wort vom Kreuz als rhetorisch erzeugtes Bild ${ }^{24}$ vom Kreuz zielt darauf, glauben zu lassen und die Hörer oder Leser so glauben zu machen. Gegen solch einen Anspruch regt sich scilicet Widerspruch im Namen der Unverfügbarkeit. Der Übergang vom Sehenlassen und -machen zum Glauben machen (es sei so, wie gezeigt) ist leicht gesagt, aber unmöglich zu fassen und zu machen, ein simpossibleく. Etwas so zu zeigen und es dazu zu machen bis zum Glauben machen sind hyperbolische Wendungen. Von Gottes Wort mag das gesagt werden und gelegentlich auch gelten: Was er sagt, geschieht und ist, wie gesagt (Ps. 33, 9), auf dass ihm geglaubt werde. Aber solch ein Übergang vom Wort zum Glauben ist ungeheurer Überschwang. So wie schon das Verstehen seitens der Adressaten bestenfalls ermöglicht und erleichtert werden kann, wird etwas $\mathrm{zu}$ verstehen und $\mathrm{zu}$ sehen gegeben, mehr nicht. Kann das Wort doch unmöglich die Adressaten auch >nehmen machen: also nicht auch das Verstehen ımachen`, um wieviel weniger dann Glauben. Nur, wettet nicht genau darauf die rhetorische Evidenzerzeugung (und das ist einer der Gründe für die Rhetorikphobie): Wenn sie gelingt, macht sie uns glauben, nolens oder volens, besser: Sie trifft uns, ıspricht uns zu vor allem Wissen, Wollen und Wählen. Der Zuspruch des Wortes ist immer früher als unsere Wahl. Und das heißt auch: In Macht und Wirkung ist das Wort unwiderstehlich - wenn's gelingt.

Aber das gilt bestenfalls für die Wortmacht, nicht für das Machtwort. ${ }^{25}$ Beides ist so verschieden wie das Sagen zu haben oder wirklich etwas zu sagen zu haben. ${ }^{26}>$ Wer das Sagen hat‘, qua Amt oder Rolle, ist das Eine. Aber ob der auch wirklich etwas zu sagen zu hat, ist stets die Frage. >Das Sagen Max Weber hätte von Amt und Charisma gesprochen. Paulus beanspruchte beides zugleich, wie es im Streit mit den Korinthern scheint. Jesus war dagegen bescheidener: ohne apostolisches Amt, allein auf Wort und Wirken zu vertrauen und damit vor den Augen der Welt zu scheitern. Um so erstaunlicher, wenn ex post seine Deutungen an-

24 Wobei >Bild ` hier mehrdeutig ist: Es ist ein Bild vor Augen des Redners, ein unanschauliches Bild im Medium des Wortes und prätendiert ein von den Hörern selbst erzeugtes Bild in ihrer Vorstellung. Die Identität oder wenigstens Konvergenz dieser Bilder ist mitnichten gesichert.

25 Analog wären Machtbild und Bildmacht oder Machtkörper und Körpermacht.

26 Diese (kalkulierte) Verkürzung auf ein >Wer ist der Prägnanz geschuldet und nicht unproblematisch. Wird doch insinuiert, Deutungsmacht sei ein Handlungsvermögen von Personen. 
erkannt werden, ohne qua Amt autorisiert worden zu sein, etwa wenn ein Gleichnis so überzeugend ist, dass es zum kulturellen Deutungsmuster wird wie >Der Samariter Wenn es gut geht, hat der Deutungsmächtige auch wirklich etwas zu sagen und zu zeigen. Die Urgeste der Deutungsmacht lautet >Ich aber sage Euch ...<. Es scheint, als hätte Deutungsmacht etwas mit dem Schein des Seins zu tun, und das Scheinen lässt die Welt so oder so aussehen - oder sie lässt Christus so oder so erscheinen, als Gekreuzigten.

Wenn ein Mächtiger spricht, spricht er ein Machtwort, ${ }^{27}$ in der die Macht des Mächtigen im Wort präsent ist und wirkt, wie in Gottes Wort, im Richterspruch, der Präsidentenrede oder dem Papstwort. Die Macht des Agenten bzw. der Institution ist im >repräsentativen « Wort präsent und wirksam. Dieses Modell kommt an seine Grenzen, wenn der Repräsentant als Person unglaubwürdig wird oder Unsinn spricht. Der Grenzfall Roma locuta, causa finita mit dem Infallibilitätsanspruch von Papstworten (ex cathedra) zeigt in seinem extremen Anspruch, dass dergleichen normalerweise nicht gilt, sondern selbst das Machtwort auf Anerkennung (oder Einverständnis) angewiesen bleibt.

Die Wortmacht hingegen ist nicht die Macht des Agenten, des Amtes oder der Institution, sondern des Mediums, exemplarisch der Sprache (oder des Bildes). Nietzsches Spruch: »Ich fürchte, wir werden Gott nicht los, weil wir noch an die Grammatik glauben ... $\ll^{28}$, Wittgensteins Sprachspielmodell oder auch die Sprechakttheorie gehen von der der Sprache eigenen Macht aus, die wir in jedem Sprechen in Anspruch nehmen bzw. von ihr beherrscht werden: ১So sprechen wir eben`. Die Sprache macht vieles möglich und anderes unmöglich, so dass im Sprechen diese Vorgaben unvermeidlich in Anspruch genommen werden. Im aktualen Sprechakt zeigt sich noch eine andere Macht, die des Sprechens, wirksam zu sein kraft der Art des Sprechens (was in der rhetorischen Tradition scilicet bekannt ist): Die parole oder das Sagen im Unterschied zum Gesagten entfalten in ihrer Performanz eine andere Macht als die Sprache oder das Zeichensystem. ${ }^{29}$ Deswegen wurden Liebeserklärungen wie Beschimpfungen als (prekäre) Analogien für das verbum efficax und visibile genommen.

Was durch diese Differenz sichtbar wird, ist eine prekäre Ambivalenz in Paulus' Argumentation gegen seine korinthischen Widersacher. Selbstredend will er etwas zu sagen haben (Wort vom Kreuz), also Wortmacht entfalten; aber das wird zur Sprache gebracht mit der Geste, er habe das Sagen (als Apostel und Gemeindegründer), also mit Machtworten. Das ist prekär und untergräbt, was er wirklich zu sagen hat. In der Not

27 Vgl. exemplarisch: Robin Mishra (Hg.), Angela Merkel - Machtworte. Die Standpunkte der Kanzlerin, Freiburg i. B. 2010.

28 Friedrich Nietzsche, Götzen-Dämmerung oder Wie man mit dem Hammer philosophirt, in: ders., Kritische Studienausgabe, Band 6, herausgegeben von Giorgio Colli und Mazzimo Montinari, München / Berlin / New York 1988, 55-161; hier: 78.

29 Medienwissenschaftlich ist die Macht des Mediums (über seine `user`) das leitende Modell, ebenso wie wissenschafts- oder technikgeschichtlich; diskurstheoretisch gilt Analoges, systemtheoretisch ebenso. 
des Konflikts greift die Wortmacht zum Machtwort. Der Anspruch des Machtwortes soll die Wortmacht stärken, untergräbt sie aber. Das Problem wird nur noch verschärft, wenn für das Machtwort eine singuläre, exklusive Ermächtigung in Anspruch genommen wird: die Apostolizität. Dann wird die Geste des Machtworts überhöht mit dem Anspruch, es sei Gott selbst, der dies autorisiere - und wer gegen Paulus stehe, stehe gegen Gott und Gott gegen ihn.

Das zeigt eine traurige Ohnmacht: Das Wort sucht Macht, mehr Macht, als es von sich aus hat, und verirrt sich in Machtgesten, die zu eskalierender Selbstermächtigung führen. Der unbedingte >Wille zur Macht $`$ als Gewand des >Willens zur Wahrheit $`$ führt in die Irre, so dass nur noch die Flucht in eine Hyperbolik der Ermächtigung bleibt. Wer das Wort vom Kreuz dergestalt als Wort Gottes zur Geltung bringen wollte, dass im Ersten und Letzten das Machtwort herrsche, überließe der Macht das letzte Wort. Die ultima ratio ist dann folgerichtig die Exklusion derer, die sich diesem Machtanspruch nicht beugen. Die Genealogie der Häretisierung im Namen der Orthodoxie ist so nur zu verständlich - und vergebens, oder soll man sagen: > umsonst`? Im Zeichen des > Wortes Gottes kann es nur zu leicht zum Machtwort gemacht werden, wenn die Wortmacht, die Macht des Wortes allein nicht die gewünschte Anerkennung zeitigt. Eine Pathologie der Theologie ist auch aus dem Konflikt in Korinth ableitbar - ohne damit zu unterstellen, dass dieselbe bereits bei Paulus vorläge.

\section{Wirkliche Unmöglichkeit: Paulus sfolie de l'impossibler}

Im Blick auf das Begehren nach Vergebung notierte Derrida: »Die reine und bedingungslose Vergebung, um den eigentlichen Sinn zu benennen, darf keinen `Sinn haben, keine Finalität, sogar keine Intelligibilität. Das ist eine Torheit des Unmöglichen.« (»Le pardon pur et inconditionnel, pour avoir son sens propre, doit n'avoir aucun ısens`, aucune finalité, aucune intelligibilité même. C'est une folie de l'impossible. «) ${ }^{30}$ John Caputo folgte ihm mit seinem >desire to experience the impossible und seiner sapology for the impossible $\triangleleft .{ }^{31}$ Die >folie de l'impossible - das ist wunderbar erdacht und weise gesagt. Nur was lässt einen darauf vertrauen oder sicher sein, dass das keine impossible folie sei, keine unmögliche Torheit?

Gegenüber Derrida könnte man einwenden, es sei ja alles andere als eine riskante folie, wenn man das so verbreitete Bedürfnis nach Vergebung bediene. Insofern riskiert er wenig, wenn er Aufmerksamkeit, Resonanz und weitgehende Anerkennung erwarten kann. Die Vergebung allerdings für unmöglich zu erklären, weil im Ernst nur von Vergebung zu sprechen sei, wo es um das Vergeben des Unvergebbaren gehe, das

30 Vgl. Jacques Derrida, Le siècle et le pardon, in: Le Monde des Débats,12 (1999) 10-17. 31 Vgl. John D. Caputo / Michael J. Scanlon (Hg.), God, the gift, and postmodernism, Bloomington 1999, 3. 
ist eine wunderbare Wandlung des Problems, ähnlich Schleiermachers sunendlicher Aufgabe des Verstehens. Dann wird Vergebung im Ernst zum Objekt infiniten $B e$ gehrens, dessen Hunger nie wird gestillt werden könne. Nur - dieses Paradox wäre schnell entparadoxiert, wenn es in negative und positive Unmöglichkeit auseinander tritt: Negativ unmöglich ist Vergebung kein Vermögen des homo capax. Das ist gegen Ricœur mit der jüdischen wie paulinischen Tradition gut getroffen. Bis heute gibt es keine Gebrauchsanweisung für `Vergebung «, weil wir nicht wissen, wie man das macht. Es gibt kein Vermögen, das dem entspräche. Und der schlichte Grund ist: Keiner kann das, wenn es im Ernst um Vergebung geht. Deswegen war eine der großen Häresien Jesu die Sündenvergebung, weil sie als Privileg Jahwes allein galt. Positiv unmöglich ist die Vergebung, sofern sie dann - falls seinesgleichen geschähe - eine diesseits aller Möglichkeiten liegende Ermöglichung wäre. Unmöglich ist das Jenseits der Möglichkeit, das ermöglichen kann. Insofern sind ja auch `Bedingungen der Möglichkeit`selber nicht möglich (sondern notwendig oder `mehr als notwendig`), stehen also (angeblich) nicht zur Disposition, denn sie ermöglichen erst alles weitere. So tritt die Unmöglichkeit der Vergebung kritisch auseinander, in das, was uns unmöglich ist und bleibt und das was uns alles andere ermöglicht. Und damit könnte man sich beruhigen. Das Paradox wäre perdu.

Entsprechendes kann auch bei Paulus passieren. Seine Umwertung aller Werte von Weisheit und Torheit ist prima vista paradox: Die Weisheit dieser Welt sei vor Gott doch nur Torheit. Und Gottes Weisheit sei vor der Welt doch nur Torheit. Nur ist das noch lange kein Paradox, sondern schlicht ein Gegensatz, der auf eine Perspektivendifferenz zurückgeht: Was die einen für weise halten, hält der andere für töricht - und umgekehrt. Ein normaler Dissens, genauer gesagt: Ein konträrer Gegensatz, der noch lange nicht ausschließt, dass es ein Drittes oder Viertes gäbe, das weiterführt. Der Gegensatz wird von Paulus allerdings entscheidend verschärft: Die Weltweisheit sei blind für Gott. Denn er hat sie szur Torheit gemacht (soll das heißen: mit Blindheit geschlagen? Oder nur im Lichte seiner Weisheit als unterlegen oder unnütz erwiesen?) Jedenfalls führt er den Agon in einen Komparativ - der paradox klingt: Die Torheit Gottes sei weiser (1, 25: tò

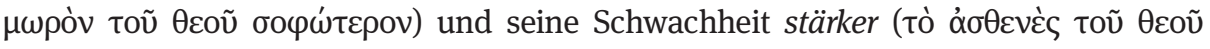
ioxupótepov). Wie mit dem Kreuzestitulus INRI wird auch hier die polemische Fremdbezeichnung für Christus (Torheit) offensiv und polemisch aufgenommen - und umbesetzt. Diese Torheit (wenn sihr es so nennen wollt), ist die eigentliche Weisheit. Und wie im ontologischen Argument Anselms (quo maius), steht hier nicht ein Superlativ, sondern ein Komparativ (weiser, stärker). Damit wird eine unausdenkbare Weisheit angedeutet, die simmer noch größer, höher, weiter ist, als alle Welt.

Das primäre Paradox der törichten Weisheit und weisen Torheit zerfiel in einen konträren Gegensatz. Der paulinische Sprachgebrauch ist dabei klar Partei und seinseitig ‘ coram Deo gesprochen. So ist klar, dass er in seiner Perspektive das Paradox schon entparadoxiert: Was die eigentliche Torheit ist und was die Weisheit, ist nie klärungsbedürftig, sondern immer schon klar und eindeutig. Die unerfreuliche Nebenwirkung

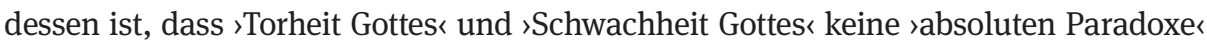
sind (wie keine absoluten Metaphern), sondern äußerliche Paradoxien. Es wird die 
Polemik der anderen aufgenommen und umbesetzt überboten. Eine echte Torheit Gottes gibt es nicht im Duktus dieser Rhetorik. Und das hat die Folge, dass auch die parallel gebaute >Schwachheit Gottes` eigentlich gar keine Schwachheit ist.

Aber durch den Komparativ kommt der schlichte Gegensatz in Bewegung: es gibt weisere Weisheit (und törichtere Torheit). Damit wird die Torheit dreideutig:

Erstens: was die Weltweisheit für töricht hält,

Zweitens: was Gott für töricht hält,

Drittens: was Paulus als die weisere Weisheit verkündigt: die törichtere Torheit im Lichte der Weltweisheit, also eine plus impossible folie, die kraft der Wortmacht aber christologisch immer noch klüger ist als die Weltweisheit. Was der als nur noch unmöglicher erscheint, ist die folie de la plus impossible, des Gekreuzigten also. Damit wird Paulus' Weisheitsrede von der weiseren Weisheit zur Figur des Dritten, zum >Mittler im Widerstreit von Gottes Torheit und Weltweisheit. Er ist es mit seiner Wortmacht, der der Welt die weisere Weisheit Gottes zeigt - und Gott die törichte Weisheit der Welt. Er vertritt den Einen vor den Anderen - und die Anderen vor dem Einen. Das Eine vor den Anderen, die Anderen vor dem Einen - wodurch beide anders aussehen und einander anders sehen können als bisher. Nicht Gottes Macht oder das apostolische Machtwort, sondern die paulinische Wortmacht bringt die Umwertung aller Werte: Die weisere Weisheit Gottes erschien zunächst als plus impossible folie; zeigt sich im Laufe der Rede aber als Leid und Leidenschaft des mehr als Unmöglichen: des Gekreuzigten. ${ }^{32}$

Die dann entstehende Rückfrage lautet: Ist die Rhetorik des Paulus eine Weisheit vor Gott oder eine Torheit? Und eine Torheit vor der Welt oder eine Weisheit? Bis dahin, dass fraglich wird, ob die weisere Weisheit von Gnaden der paulinischen Rhetorik sei in der Hoffnung darauf, im Gekreuzigten zu gründen und nicht nur eine Erfindung in der Not des Deutungsmachtkonflikts zu sein. Die riskante Wette in dieser Wortmacht ist, dass in der paulinischen Kreuzesrhetorik beide Perspektiven so vermittelt werden, dass die Weltweisheit nicht nur exkludiert und diffamiert wird, sondern aufgehoben und über ihre Grenzen hinausgetrieben - gezogen von der weiseren Weisheit, die im

32 Es ist daher verständlich, dass Otfried Hofius und Cilliers Breytenbach darum stritten, ob das Wort vom Kreuz nur ein für alle Mal die Welt versöhnt hat oder ob es weiterhin versöhnt (zu 2 Kor. 5, 19a), also ob das katallassein (in der coniugatio periphrastica) gegenwärtig dauert und künftig weitergeht, oder es immer schon abgeschlossen und geschehen ist. Grammatisch gilt: Es war einmal. Rhetorisch gilt: Es dauert an. Paulus wird zum (nicht selbsternannten) Mittler. Vgl. Cilliers Breytenbach, Versöhnung. Eine Studie zur paulinischen Soteriologie, Neukirchen-Vluyn 1989; Otfried Hofius, Rezension von Breytenbach, Versöhnung, in: Theologische Literaturzeitung 115 (1990) 741-745; Cilliers Breytenbach, Abgeschlossenes Imperfekt? Einige notwendig gewordene Anmerkungen zum Gebrauch des griechischen Imperfekts in neutestamentlichen Zeiten, in: Theologische Literaturzeitung 118 (1993) 85-91; Otfried Hofius, 2 Kor 5, 19a und das Imperfekt, in: Theologische Literaturzeitschrift 118 (1993) 790-795, sowie Ferdinand Hahn, Streit um »Versöhnung«: Zur Besprechung des Buches von Cilliers Breytenbach durch Otfried Hofius, in: Verkündigung und Forschung 36 (1991) 55-64. 
Gewand der Rhetorik zur Sprache kommt. Der Preis solch riskanter Rede ist, dass sie zu einer konstitutiv ambivalenten Figur wird. Nichts verständlicher, als dass sich an Paulus die Geister scheiden. Insofern trägt er die Last der Welt und Gottes. Die oben explizierte traurige Ohnmacht und Eskalation der Machtgesten - ist der Preis der weiseren Weisheit, den er nicht vermeiden kann. Es muss absurd erscheinen, was er bezeugt - auf dass in dieser Absurdität sich deren Kalkül zeigt.

Dialektischer Schwindel mag einen beim ersten Hören erfassen, und bei der ersten gründlichen Lektüre wiederkehren. Aber - er hält nicht lang. Denn er entpuppt sich schnell als bloßer dialektischer Schein. Paulus gibt sich größte Mühe mit seiner Rhetorik, aber es ist und bleibt alles klar und eindeutig. Fraglich und wirklich strittig ist nichts. Den Juden und Griechen gegenüber wird die Umwertung aller Werte eineindeutig klar gemacht. Das stiftet und sammelt Konsens bei den christlichen Adressaten der rhetorischen Argumentation. Den innerchristlichen Gegnern gegenüber gibt es aber im Ernst Streit um die rechte Auffassung der weisen Torheit und törichten Weisheit. Dort gibt es einen echten Agon um die weisere Weisheit - mit offenem Ausgang. In Abgrenzung zu Juden und Griechen sammelt Paulus (topisch und inventiv) Zustimmung seitens der christlichen Gemeinde, um die allzu weisen, immer noch weiseren Gegner anzugreifen und vor die Alternative zu stellen: mit ihm zu rennen oder ausgeschlossen zu werden. Nachdem den Juden und Griechen gegenüber bereits ein Agon der Weisheit eröffnet wurde (mit feststehendem Sieger, also ein abgekarteter Agon), kann dieser innerchristliche Agon zum echten Problem werden.

Denn die höhere, größere, weitere Weisheit wird wohl zuerst und gerade von den Gegnern beansprucht worden sein, die Paulus entgegentreten und seine Theologie süberholen ‘ wollen. Wir sind nicht nur des Paulus, auch nicht des Teufels - sondern wir sind Christi! Wir sind weiser als Juden, Griechen und Paulus zusammen. Diesen Komparativ hat Paulus übernommen und spielt ihn mit, so dass er die Konsequenzen zu tragen hat. Mit weiterer Steigerung der Weisheit lässt sich das Wettrennen mit den Gegnern um die Weisheit nicht mehr gewinnen. Wie dann?

Der Agon im Dromos wird von Paulus einer innerchristlichen Umwertung unterzogen: einer Schubumkehr oder einem überraschenden Richtungswechsel. Der Dromos wird zum Palindromos: Auf offener Strecke des Wettrennens in der theologischen Arena, kehrt Paulus plötzlich um und läuft anders herum: von der Weisheit zur Torheit - und wieder zurück von der Torheit zur Weisheit. Wenn das bei einer Olympiade passieren würde, wäre es ausnahmsweise eine echte Überraschung. Als Mittler muss er hin und her zwischen Gott und Welt und Welt und Gott, zwischen Weisheit und Torheit, Torheit und Weisheit, auf dass in diesem rhetorischen Agon die weisere Weisheit aufscheint in der Weisheitsrede des Paulus. Dromos zum Palindromos, hin und her - und her und hin, das führt schließlich dazu, das er hin und zurück läuft, in einem immer kleineren Kreis, auf der Stelle kreiselt. Ist das der Punkt, von dem aus er die Weisheit der Welt aus den Angeln hebt - oder ist das ein Kreisen um sich selbst?

Für Außenstehende jedenfalls muss das mehr als absurd aussehen. Paulus staumelt ‘ hin und her, hieß es oben vorläufig. `Der spinnt doch ‘ - wäre die zu erwartende Reaktion. Ist der völlig verrückt geworden? `Keineswegs`, würde Paulus wohl antworten: 
im Gegenteil. Denn, so wohl die von ihm insinuierte Voraussetzung, die Gegner haben einen Fehlstart hingelegt, oder heute könnte man sagen: Sie sind gedopt. Denn irgendwie wird in all ihrer Weisheit die Torheit vergessen: das Kreuz übersprungen hin zur Auferstehung. Ihnen fehlt die Erdenschwere Gottes, die Ohnmacht Christi und die Leibhaftigkeit christlicher Existenz. Soteriologische Ungeduld könnte man das nennen: das Überspringen des Alten ins Neue. Das Begehren nach Vollendung überspringt die Arbeit am Alten. Sie sind nicht nur weise, sondern sallzu weise .

Wolfgang Schrage nannte die Position der Gegner, ob es eine Christuspartei gegeben haben mag oder nicht, »Weisheitshypertrophie « ${ }^{33}$. Ob das gleich eine Gnosis sei, wie die Schüler der religionsgeschichtlichen Schule meinten (bis Walter Schmithals), oder ob das eine prägnostische oder gnoseogene Gruppe gewesen sein mag, mögen Historiker klären. Es ist jedenfalls der implizite Leser bzw. Adressat der Argumentation, die die Weisheit nicht nur exkludieren kann und gegenbesetzen (gegen Juden und Griechen), sondern sie aufnehmen und umbesetzen muss. Die Gegner werden also nicht mit Juden und Griechen exkludiert, sondern seingeholt und eingefangen<, ihre Parole aufgenommen, aber paradox umpointiert: Weisheit ja, auch weisere Weisheit. Aber der Komparativ der Weisheit gründet in der christologischen Pointierung - und die kann nicht mit Pneuma und Auferstehung gewonnen werden, sondern nur mit dem Kreuz.Wer das überspringt oder im Wettlauf der Weisheit verliert, hat den rechten Start verpasst.

Was Paulus da treibt, mit allen Mitteln der Wortmacht, kann man mit Derrida sfolie de l'impossible nennen. Oder mit Erasmus ein Lob der Torheit. Aber weder kennt Derrida einen gekreuzigten Messias noch Erasmus einen toten Gott oder eine sterbliche Seele. Beiden bleibt die eigentliche Härte undenkbar oder unmöglich. So gesehen erscheint selbst Derridas sfolie de l'impossibler noch leichtfüßig und etwas allzu weltweise. Von Erasmus gilt das bekanntlich ohnehin. Letztlich sind beide sgut bekömmlich - und damit harmlos. Die paulinische Pointe ist die folie de la plus impossible: die unmögliche Wirklichkeit des Gekreuzigten. Wenn selbst Derridas folie so gesehen fast harmlos erscheinen kann, zeigt sich in dieser anderen Art zu sehen die Deutungsmacht der paulinischen Argumentation: Sie lässt und macht sehen, so und anders als bisher. Und zwar so, dass nicht allein das Zeigen, sondern das Gezeigte darin eine Deutungsmacht entfaltet: der Gekreuzigte im Modus der Wortmacht des Wortes vom Kreuz. Es ist überaus unselbstverständlich, wenn nicht unverständlich, dass der Gekreuzigte als maßgebende Schubumkehr, als sapientiales Palindrom, verstanden und am Ende gar anerkannt wird. Paulus wettet mit seiner Weisheitsrede auf die Realpräsenz des Verkündigten in der Verkündigung. Daher ist verständlich, dass seine Rede, geronnen als Text, später sakramental aufgefasst werden kann. Aber auch hier gilt wie im Blick auf Gottes Wortmacht: die Macht des Wortes kann nur Deutungsmacht sein, die dem Gedeuteten zugeschrieben, übereignet werden muss und doch sie selber bleibt, bloßes Wort.

33 Schrage, Der erste Brief an die Korinther, 150. 
Dieses Wort dem zu übereignen, der darin gedeutet wird, ist eine paradoxe Gabe: in der Paulus deutend dem Gedeuteten seine Deutungsmacht leiht, von dem er sie empfangen zu haben glaubt, auf dass die Hörer in Paulus Weisheitsrede die weisere Weisheit am Werk sehen. Diese Wette auf den Christus praesens ist und bleibt offen und kann gewonnen werden allein durch die Leser oder Hörer - und auch aus deren Kraft oder Vernunft nicht. Es ist eine Wette sà fond perdu durch ein Machtwort den Wettausgang entscheiden wollte, hätte schon verloren.

Würde der Gedeutete in der Deutung als Deutung real gegenwärtig, wäre das in der Tat, genauer: in dem Leid, ein persistentes Paradox. Irritierender Weise wird dieses >Wortereignis` im Wettlauf um die weisere Weisheit von Paulus eher gefährdet als exponiert, wenn er die >Torheit ` immer druckvoller zur Sprache bringt. Er wechselte die Richtung, hin und her - und muss den Anderen, die weiterlaufen, andemonstrieren, dass sie in die falsche Richtung laufen. Und da hilft nur ein Machtwort: apostolische Ermächtigungsrhetorik pro domo, und zugleich Entmächtigungsrhetorik polemisch an die Gegner adressiert. Die Ökonomie dieser Rhetorik ist bekannt: Universalisierung der Inklusion - mit gleichzeitiger Produktion des absoluten Restes. Schlichter gesagt: Inklusion durch Exklusion und Exklusion durch Inklusion mit dem gefährlichen Ausgang einer apokalyptischen Dualisierung: Wer nicht mit uns ist, ist wider uns. Gott und Welt treten gegeneinander wie Apostel und Gegner - bis dahin, dass die Welt als feindlich dualisiert wird. Johannes ist bekanntlich einen ähnlichen Weg gegangen, bis die Protognostiker in der johanneischen Gemeinde das übertrieben haben. Solche Dualisierung ist theologisch wie rhetorisch nicht besonders weise. Denn sie produziert nicht nur mehr Probleme als sie vermeintlich löst. Sie unterschreitet auch die Aufgabe der apostolischen Rhetorik: Mittler zu sein, nicht Inquisitor.

\section{Deutungsmachtergreifung: Flucht ins apostolische Amt}

Eine Konsequenz dieser rhetorischen Eskalation ist die spätere Institutionenpolitik des apostolischen Amts: die Härtung der Wortmacht als Machtwort und darüber hinaus schlicht als institutionelle Macht, die jeder Semantik entbehren kann. Das Amt dient dann der Sicherung des Charismas bis zur spätaugustinisch extremen These: die Institution wie das Amt sicherten die Heilsvermittlung auch ohne jedes Charisma. Form ohne Geist wäre der leblose Grenzwert dieser Entwicklung.

Aber so weit ist es bei Paulus noch lange nicht. Nur die Grundfigur wird hier serfunden` (zumindest fungiert sie ex post als Ätiologie des Amtes). >Urstiftungく hieße das phänomenologisch. An der Grenze der Wortmacht ist auch dem Apostel das Machtwort recht und billig. Am Scheideweg von Wortmacht und Machtwort konnte es die >Interpretationsgemeinschaft` offenbar nicht lassen, der Versuchung nicht widerstehen, die Macht des Wortes durch ein `höhere Macht zu begründen, mit absoluter Letztbegründung durch Apostolizität. Der >Apostel Paulus` wurde so zur >Kunstfigur`, 
zum Produkt der rhetorischen Technik, mit Deutung immer noch mehr Deutungsmacht zu erzeugen, die als Selbstdeutung der Macht ausgegeben wird.

Die Figur >des Apostels` wird als `Erwählter` vor Augen gemalt und zu seinem Amt mirakulös >Berufener` - und führt seitdem ihr deutungsmächtiges Eigenleben. Um nicht missverstanden zu werden: Erstens geht es damit nicht um den historischen Saulus namens Paulus, sondern zweitens um den biblischen, kanonischen Paulus, der als Regulativ der symbolischen Ordnung des Kanons im Kanon gilt und damit zur >Mitte der Schrift ` wird. Damit aber wird ein >Mehr als Schrift prätendiert, drittens: ein imaginärer Paulus, der Apostel als metahistorische Kunstfigur, der schließlich in der Rezeption vom Verkündiger zum Verkündigten geworden ist: vom Missionsprediger zur norma normans (non normata?) aller Predigt, also nicht nur zum Predigtgegenstand, sondern viertens per impossibile zum apostolischen Dispositiv aller Predigt, die als Gottes Weisheit soll auftreten können.

Wie kam es dazu? - Und welche `Textsignale bieten die Möglichkeit dazu? Der Prediger in der Krise beansprucht Charisma, das ihm offenbar nicht selbstverständlich und in unstrittigem Konsens zugeschrieben wurde. Insofern ist seine Deutungsmacht liminal im Ausnahmezustand: Sie ist nicht etabliert, sondern steht im Streit zur Disposition. Und das ist bereits eine prekäre Lage: Ecce apostolus. Dann muss Deutungsmacht aufgebaut werden, die ihm nicht >von unten • bereits zuwächst. Im Konfliktfall kann die Durchsetzung dieses Anspruchs auf das Andere des Charismas rekurrieren: Amtsvollmacht durch externe Beauftragung als pneumatologische Paratheorie zur Deutungsmachtergreifung. Der Anspruch auf Wortmacht verschiebt sich zum Machtwort: auf das Amt als Funktion des Charismas mit Exklusivität und Singularität des Amts.

Im rhetorischen Agon mit den Gegnern gerät die Argumentation später, im zweiten Korintherbrief, auf eine sschiefe Bahn`, in der die Geltungsansprüche dergestalt eskalieren. 2. Kor 12, $11 \mathrm{f} .:$ »Denn ich sollte von euch gelobt werden, da ich doch nicht weniger bin als die Überapostel, obwohl ich nichts bin. Denn es sind ja die Zeichen eines Apostels unter euch geschehen in aller Geduld, mit Zeichen und mit Wundern und mit Taten. « ${ }^{34}$ Das klingt nach einer Apostelolympiade: höher, weiter, größer heiler, vollendeter und weiser. Das ist vielleicht nicht ohne Ironie zu hören. Klingt es doch nach einer Heilskompetition, die immer noch mehr begehrt - und damit ihren eigenen Mangel produziert.

Ist es wirklich noch Gottes Torheit, seine weisere Weisheit, die hier zur Sprache und zur Geltung gebracht wird? Was passiert in solch einer Deutungsmachtkompetition? Aus Worten Macht zu schlagen, wie aus Steinen Funken und Feuer, ist eine wundersame Erzeugung von Deutungsmacht. Der Anspruch darauf eignet jedem Wort. Aber dass das auch ızündet` - ist nur mit dem Zunder der Hörer denkbar. Und um es

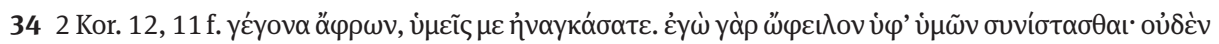
yà

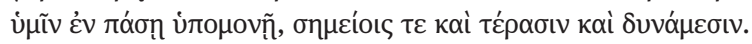


nicht denen allein zu überlassen, tritt hier noch eine pneumatologische Reserve ein. Deutungsmacht, die wirklich zündet, sei im Grunde racheiropoietisch`, nie von Menschenhand gemacht: eben Gotteswort, nicht Menschenwort.

Aber auch noch dieser Deutungsmachtanspruch kann nur eingelöst werden durch Ratifikation seitens der Adressaten. Und das ist Paulus anscheinend in Korinth nicht gelungen. Ist die Gemeinde doch im Laufe der Zeit verschwunden, als wäre sie zersplittert und zerstreut worden. Die maßgebende Ratifikation erfolgte je später, desto mächtiger. Die imaginäre Kunstfigur des Apostels wurde - nicht ohne imaginären Überschwang - zum kanonischen Modell für Geltung jenseits ihrer historischen und rhetorischen Genesis. Die rhetorische Erzeugung des apostolischen Wortes musste vergessen gemacht werden, damit dessen Geltung von der Genesis gelöst auch für alle Zeit Bestand haben kann. An die Stelle der rhetorischen Genesis seiner Wortmacht trat die divine Genesis des Apostolats als Geltungsgrund des institutionellen Machtwortes.

Die rhetorische Fabrikation des apostolischen Machtanspruchs operierte mit Autorisierungslegende, Autorisierungssymptomen, Autorisierungsgesten und -semantik - in summa: mit einer Autorisierungstechnik. Wenn man ihr folgt, vermag sie, die Wortmacht durch das Machtwort zu begründen und final zu ersetzen. Die supplementären Begründungstechniken entlasten von Rückfragen, indem sie der Macht das erste und letzte Wort lassen. Dann würde auch die offene Wahrheitsfrage und -suche entbehrlich, weil sie `qua Amt ` bereits entschieden wäre. Das ist für eine Institution ungeheuer beruhigend - aber im religiösen wie im theologischen Diskurs sunsäglich`. Müsste nicht das Machtwort auf Fragen der Wortmacht zurückgeführt werden: auf Deutungsmacht statt Machtdeutung?

I. Die apostolische Autorisierungstechnik beginnt schon mit der Überschrift, dem Titel des Textes wie des Verfassers: Der Titel apostolos in Röm. 1, 1;1 Kor. 1, 1; 2 Kor. 1, 1; Gal. 1, 1 dient dazu, seine Botschaft zu legitimieren: »Apostel nicht von Menschen und nicht durch einen Menschen, sondern durch Jesus Christus und Gott, den Vater« (Gal. 1, 1). Nicht alle Osterzeugen sind Apostel, aber alle Apostel Osterzeugen. Daher ist konstitutiv die Berufungsvision (1 Kor. 9, 1; 15, 9; Gal. 1, 15) und zur Vision kommt die Beauftragung durch Gott selbst zur `Mission ‘ als Charis (Röm. 1, 5; 15, 15;1 Kor. 3, 10; Gal. 1, 15; 2, 9), d.h. die Beauftragung zur Mission, also Gemeindegründung. Im 1 Kor. ist das einleitend dominant präsent: 1, 1: »Paulus, berufen zum Apostel Christi Jesu durch den Willen

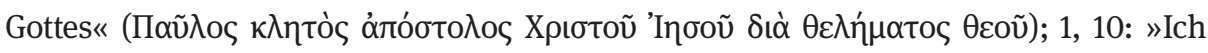
ermahne euch aber, liebe Brüder, im Namen unseres Herrn Jesus Christus, dass ihr alle

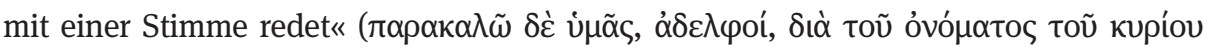

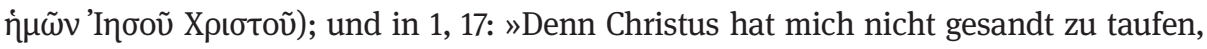

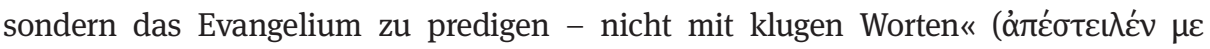
Xрıбтós). In summa heißt das ego eimi: Ich bin der berufene Apostel, vertrete Gottes 
Willen und bin sein Gesandter, spreche und ermahne daher im Namen Christi mit der christologischen Zusatzthese: Jesus ist Jahwe (kyrios-Titel für Christus ${ }^{35}$ ).

II. Grundlegend für die Fabrikation der imaginären Figur namens >Apostel Paulus` ist im Anschluss an diese Textsignale die Autorisierungslegende, wie sie (wiederum selbstautorisierend) ein Literat im Namen des Apostels Lukas erfunden hat. Die Legende seiner Vision und Berufung malt eine strikt private Vision vor Augen, die als öffentlich wirksame Autorisierung ausgegeben wird. Prophetischer Topik verpflichtet wird durch eine Machtoffenbarung aus dem alten Eiferer der Apostel ıwider Willen oder saus Versehen`. Hat er doch diese Zeugenrolle weder gewünscht noch gewählt, sondern er sei erwählt und die Aufgabe auferlegt, ohne gefragt worden zu sein.

Ricœur erörterte Analoges in den theologischen Teilen seiner Gifford-Lectures als Antwortcharakter des Selbst, das er als sujet convoqué und soi mandaté konzipiert. ${ }^{36} \mathrm{Er}$ analysiert den sappel<, den Anspruch der Schrift, und deren stotale étrangeté، ${ }^{37}$ Die drei Teile des Alten Testaments, Tora, Propheten und Schriften, bedeuten »l'un sur l'autre le moment de l'appel et celui de la réponse ${ }^{38}$. Die Polyphonie und Dezentriertheit der Schrift zeige eine "pluralité des figures de réponse « ${ }^{39}$. Deutlicher noch: "C'est ainsi qu'au ternaire de l'appel - Torah, Prophètes, Sagesse - répond le système ternaire de l'identité fondée, de l'identité ébranlée, et de l'identité à la fois singularisée et universalisée ${ }^{40}$. In dieser Trias kann man eine konkretisierte Version des $>$ Dreifuß der Passivität entdecken, in der das basale Eigenleibverhältnis, das Alteritätsverhältnis und das interne Verhältnis zum Gewissen variiert und wiederholt werden. Auf diesem Hintergrund erscheint auch die Identität des Apostels Paulus als sujet convoqué im soi mandaté.

Nur diente die Autorisierungslegende im Konfliktfall zur Ermächtigung nicht nur seiner Verkündigung und Mission, sondern auch seiner theologischen Argumentation: »Bin ich nicht Apostel? Habe ich nicht Jesus, den Herrn gesehen?« (1 Kor. 9, 1). Wer das betonen muss, streut bereits Zweifel. Und das nicht ohne Grund. Von den Gegnern dürfte die Behauptung stammen: »Seine Briefe, sagt man, sind gewichtig und stark, seine körperliche Anwesenheit schwach und seine Rede nichtswürdig« (2 Kor. 10, 10). Der Wechsel von der Wortmacht in das Machtwort und dessen divine Letztbegründung - ist ein Symptom der Krise, der Fraglichkeit, wenn die Wortmacht nicht mehr satis est.

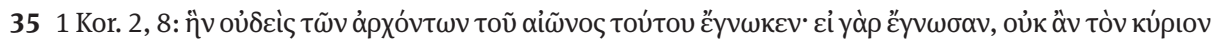

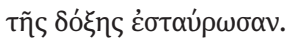

36 Vgl. Paul Ricœur, Phénoménologie de la Religion (1), in: Revue de l'Institut Catholique de Paris 45 (1993) 59-75.

37 Vgl. Ricœur, Phénoménologie, 66, mit Frye.

38 Ricœur, Phénoménologie, 73.

39 Ricœur, Phénoménologie, $73 \mathrm{f}$.

40 Ricœur, Phénoménologie, 74. 
III. Sein Gewicht als Christi Apostel (1 Thess. 2, 6f.) wird dann auch in Autorisierungssymptomen ausgestellt: den persönlichen Zeichen der Schwäche ${ }^{41}$ (astheneia 2 Kor. 10-13). So kann selbst Krankheit als öffentlich anzuerkennende Autorisierung geltend gemacht werden. Bei noch so großer Schwäche und Ohnmacht wird die christologische Figur zur Selbstdeutung und Selbstermächtigung geltend gemacht: eine immer noch größere Stärke und Macht. Damit wird zum einen das Autorisierungssymptom ausgestellt und intentional genutzt zur Autorisierung. Dass dabei auch eine Rationalisierung des eigenen Leidens betrieben wird als christomorph und mimetisch, ist ein weiteres Problem - das Schule gemacht hat. Vor allem aber kann, ja darf die Schwäche eines Verkündigers und Theologen als Erwählungssymptom ausgegeben werden? Wird damit nicht nolens volens Christus missbraucht zur Autorisierung der eigenen Rede, für die nur Paulus selbst die Verantwortung tragen kann? Der eigene Deutungsmachtanspruch ist und bleibt undelegierbar.

IV. Der Legende und den Symptomen (die zu Autorisierungssymbolen rationalisiert werden) entsprechen die rhetorischen Autorisierungsgesten und deren Semantik, wenn in 2 Kor. 10-13 das tapeinos-Sein (Unterwürfigkeit) als Machtverzicht und -losigkeit geltend gemacht wird, deren er sich >um Christi willen` rühmt. Sein Argument hat die Form einer Analogie oder Entsprechung: Wie in Christus die Schwachheit die Form der Hoheit war, so auch bei Paulus. Es ist eine Analogie, mit der die Christomorphie des Apostels als Geltungsgrund seiner Rede inszeniert wird. ${ }^{42}$

Was für eine Analogie hier in Anspruch genommen wird, ist klärungsbedürftig: Ist es eine analogia relationis: wie Gott zu Christus so Christus zu Paulus? Oder ist es eine analogia attributionis: Christus und Paulus ist die Schwäche gemein, und daher auch die Macht Gottes? Die Analogiedifferenz ist relevant, weil im Falle einer Attributionsanalogie beansprucht würde, es gäbe ein ssubstantiell identisches` Tertium von Paulus und Christus: die leibliche Niedrigkeit und geistliche Hoheit, die Machtlosigkeit wie die Mächtigkeit. Dann würde beansprucht, die Macht des apostolischen Wortes ist die Macht Gottes. Der Apostel würde zur lebendigen Hostie - mit dem Risiko, dass er sakramental gedeutet würde, und recht verstanden umgehend ıkonsumiert werden müsste. Im Falle der Relationsanalogie würde nur eine identische Proportion beansprucht, so dass die Macht des apostolischen Wortes nicht identisch wäre mit der Macht Gottes. Das Problem ist, dass diese Analogiedifferenz anachronistisch an den Text

41 Gal. 4, 13 f.: »Ihr wisst doch, dass ich euch in Schwachheit des Leibes das Evangelium gepredigt habe beim ersten Mal. Und obwohl meine leibliche Schwäche euch ein Anstoß war, habt ihr mich nicht verachtet oder vor mir ausgespuckt, sondern wie einen Engel Gottes nahmt ihr mich auf, ja wie Christus Jesus. « und 1 Kor. 9, 22 f.: »Den Schwachen bin ich ein Schwacher geworden, damit ich die Schwachen gewinne. Ich bin allen alles geworden, damit ich auf alle Weise einige rette. Alles aber tue ich um des Evangeliums willen, um an ihm teilzuhaben.«

42 Vgl. Christine Gerber, Paulus und seine >Kinder schen Briefe, Berlin / New York 2005, 236: »In seiner Schwäche ist die Kraft Gottes resp. Christi wirksam«. 
herangetragen wird und jede Entscheidung nur eine Interpretationsentscheidung sein kann, letztlich eine selbst zu verantwortende Deutung des Interpreten.

Aber es lässt sich auf einem Umweg vielleicht doch entscheiden. Wird die Macht oder Kraft Gottes des Paulus als vis aliena ${ }^{43}$ ausgegeben und in Anspruch genommen oder als die ihm qua Apostelamt eigene Macht und Kraft? Ist die Gabe der exousia echte Gabe, oder nur Leihgabe, also Vollmacht des Apostels oder nicht? Wenn diese Differenz ohnehin bestritten wird, würde damit bereits zugestanden, dass Paulus selber mit der Macht Christi aufträte und operierte: also die vis aliena Christi für seine Worte geltend macht. "Denn die Waffen unsres Kampfes sind nicht fleischlich, sondern mächtig im Dienste Gottes, Festungen zu zerstören. Wir zerstören damit Gedanken und alles Hohe, das sich erhebt gegen die Erkenntnis Gottes, und nehmen gefangen alles Denken in den Gehorsam gegen Christus. " (2 Kor. 10, 4 f.). ${ }^{44}$ Fast riecht man schon die später aufziehenden Schwefelschwaden der Inquisition, der solche Kriegsrhetorik natürlich nur willkommen war.

Die widerfahrene oder zugezogene ripse-Identität des Paulus wird als idemIdentität, als seine neue, ihm singulär und exklusiv zueigene Identität zur Sprache und als apostolischer Anspruch zur Geltung gebracht. Die Genese seiner selbst (als Apostel) wird als Grund der Geltung seiner Rede ausgegeben. In Deutungsmachtkonflikte verstrickt, wird von Paulus (genauer: im späteren institutionellen Gebrauch seiner Figur) eine allen Konflikten entzogene und enthobene Autorisierung in Anspruch genommen, um den Konflikt kraft seiner Deutung zu entscheiden und zu siegen. Das wäre vitiös. Im Horizont der >Weisheit dieser Welt « kann es nur absurd erscheinen, in Deutung als Deutung zur Geltung bringen zur wollen, was nicht Deutung sei. ${ }^{45}$ Der apostolische Anspruch, vom Anderen der Deutung her zur Deutung ermächtigt zu sein, so dass in der eigenen Deutung dieses Andere selbst zur Sprache komme, ist eine ganz ungeheure Hyperbolé. Das ist scilicet noch nicht ein Amt im späteren Sinne (des dritten oder vierten Jahrhunderts). Aber es ist ein Autorisierungsmodell, das zum institutionsbildenden Modell gemacht worden ist: eine >Beamtung ‘ ex post, um spätere nach dem Modell zu autorisieren, nicht mehr durch eine Vision und Audition, sondern durch >Institution`. So hat die paulinische Rhetorik und Semantik nicht nur Schule gemacht, sondern `Kirche`, indem sie Institutionentheorie geworden ist - in apostolischer Sukzession mit dem Anspruch auf Apostolizität der Kirche (römisch: der historischen Amtssukzession, protestantisch: der Lehrsukzession). Sollte nicht vielmehr gelten: Keiner der Späteren konnte für sich beanspruchen, was Paulus für sich beanspruchte? Und schon Paulus konnte nicht selber für sich beanspruchen, was seine Texte beanspruchen?

43 Vgl. Schrage, Der erste Brief an die Korinther, 238.

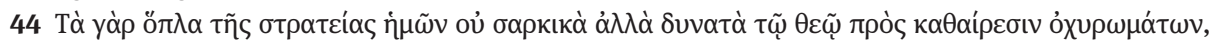

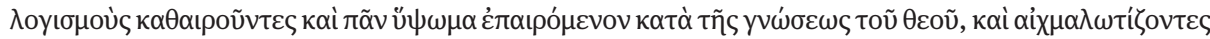

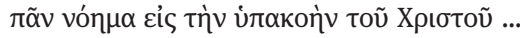

45 Es ist daher kein Wunder, dass dieser Anspruch erfolglos blieb: die paulinischen Gemeinden zerfielen, warum auch immer. 
Stattdessen Institution Institution sein zu lassen, Menschenwerk und Machwerk, und damit auch Autorisierungstechniken dieser Art sein zu lassen, um nicht Menschenwerk als Gotteswerk zu überhöhen und Wortmacht mit vermeintlich divin autorisierten Machtwort aufzuladen, wäre eine sinnvolle Deutungsentmächtigung. Aber legitimierungsbedürftige Institutionen können es anscheinend nicht lassen. Um nicht selber für diesen Deutungsmachtanspruch einstehen zu müssen, wird er an Paulus delegiert (die imaginäre Figur als norma normans), um von ihm her die Apostolizität der eigenen Position zu begründen. Dann muss dieser Paulus - ex post zum Apostel gemacht, um nicht zu sagen zum Hyperapostel der Institution - die Last der Macht tragen: die unsägliche Last der Deutungsermächtigung, um ein für alle Mal den Konflikt um die Deutungsmacht schon entschieden zu haben. Das Apostolat wurde so zur kreuzesgleichen Last, die die Unmöglichkeit ertragen muss, mit dem Machtwort die Wortmacht zu untergraben.

Man kann hier die Grundfigur der später so genannten Genealogie entdecken: die (legendarische) Genesis des Apostolats begründe und verbürge die Geltung. Nur wird `Genesis` hier doppeldeutig: Die semantische Oberfläche ist die gesagte, so gesagte Genesis durch Vision, Berufung, Erwählung und Beauftragung durch Gott selbst. Diese divine Genesis ist Grund aller Geltung (eine des Menschen Möglichkeit übersteigende Unmöglichkeit - die alles Weitere ermöglicht und verwirklicht). Aber diese gesagte Genesis ist von der gezeigten und rhetorisch gemachten Genesis unterscheidbar: Die divine Genesis gibt es für alle Adressaten des Geltungsanspruchs nur als humane Genesis, als rhetorisch erzeugte. Soll die divine Genesis Theotechnik ${ }^{46}$ sein, Gottes Erzeugnis, ist die Gegebenheitsweise ein rhetorisch Gemachtes, Anthropotechnik als Erzeugung des Apostels. Die eine Genesis muss unsichtbar werden zugunsten der anderen, und diese Verschiebung ist Aufgabe der Geltungserzeugung durch Rhetorik: also Sache der Wortmacht, die das Machtwort erzeugt, dessen Macht alle Worte letztbegründen soll. »Das Wort, das unsere Worte annihiliert, um sagbar zu werden, untergräbt seine eigene Sagbarkeit ${ }^{47}$, wurde einst gegen Jüngels ontologische Letztbegründung der Metapher eingewendet. Das Problem findet sich bereits in der paulinischen Rhetorik, sofern aus ihr institutionelle Autorisierungstechnik gemacht wurde.

Später konnte mit der Geltung qua Genealogie auch die Geltung vorfindlicher Faktizität begründet werden, sofern man der Gründungsthese folgt, dass die Genesis der Kunstfigur namens >Apostel deren Geltung als Kultfigur begründet: Der Verkündiger wird nicht nur zum Verkündigten, sondern der apostolische Text zur norma normans aller Verkündigung. ${ }^{48}$ Das hat Schule und Kirche gemacht für alle sneuen

46 Vgl. Gonsalv Mainberger, Theologie - Theoxenie - Rhetorik, in: Hermeneutische Blätter 2 (1997) 610, und Boris Groys / Peter Weibel (Hg.), Medium. Religion. Faith. Geopolitics. Art, Köln 2011, 30-43; hier: 41: " 'theo-technology«.

47 Philipp Stoellger, Metapher und Lebenswelt. Hans Blumenbergs Metaphorologie als Lebenswelthermeneutik und ihr religionsphänomenologischer Horizont, Tübingen 2000, 478.

48 Dass daraus später Institutionentechnik gemacht werden konnte von der `Reichskirche`, ist bekannt. Dass demgegenüber andere christliche Kirchen eine Amtsphobie entwickeln konnten, so dass dem Amt mit 
Apostel in entsprechenden Reformen und Revolutionsversuchen. Die Diktatur der Wiedertäufer in Münster beispielsweise repetierte diese Figur zur Selbstautorisierung - wie alle ১Sektengründer`. Im Unterschied dazu spricht es für Luthers erstaunliche Diskretion, auf solch eine Selbstermächtigung verzichtet zu haben. Der gute Sinn des exklusiven Apostolats zeigt sich darin, dass es spätere Wiederholungen auszuschließen erlaubt. Dieser negative, exklusive Sinn (von dem scilicet so oder so Gebrauch gemacht werden kann) entbehrt aber des positiven: Apostolische Tradition als Exklusionstheorem ist das eine, aber ob apostolische Tradition als Wortmacht tragfähig und vorzüglich ist, ist genau so zu unterscheiden wie Machtwort und Wortmacht.

\section{Deutungsmacht als Macht der Wahrheit?}

Paulus - hier: der apostolisch autorisierte Text - steht in einer Aporie, die sich mit der Deutungsmachttheorie explizieren lässt: mit der schlichten Differenz von >das Sagen haben « und `wirklich etwas zu sagen haben`, also von Machtwort und Wortmacht: Wer etwas zu sagen hat, will auch das Sagen haben, darf aber nicht das Sagen haben wollen, weil er genau damit untergräbt, dass und was er zu sagen hat. Wer hier mehr beansprucht, als wirklich etwas zu sagen zu haben - ruiniert alles. Umgekehrt gilt: wer qua Amt das Sagen hat - braucht nicht wirklich etwas zu sagen haben, eben weil er das Sagen hat. Das ist entlastend und beruhigend, aber eben auch zugleich die Eskalation und Kapitulation im Agon um Deutungsmacht.

Die offizielle Konstitution des Amts mag im dritten Jahrhundert gegen die Gnosis erfolgt sein, aber das Modell wird erfunden mit dem apostolischen Amt im ersten Jahrhundert von Paulus, was scilicet eine sInstitution` ist, die von der späteren Institution erst zu einer solchen ernannt wurde. Was bleibt, erscheint als Konstitutionstheorie des Amtes kraft Ermächtigungstheorie. Die protestantische These ist bekanntlich nicht über die Institution und das Amt qua historischer Amtssukzession definiert, sondern apostolische Sukzession ist Sukzession der 'Lehre`, also der argumentativ plausiblen Wortmacht. Also muss 'was apostolisch ist identifizierbar sein, ohne die Ermächtigungstheorie zu teilen und sür sich` (als idem) zu beanspruchen.

Die Deutungsmacht des Textes (im Sinne der Eigendynamik der Deutung, also dessen, was er wirklich zu sagen hat) hat wirkungs- oder rezeptionsgeschichtliche Gründe: etwa in der Institutionalisierung des Amtes mit seiner Ätiologie durch das apostolische Amt, in Augustins Paulusrezeption und in Luthers Auszeichnung der theologia crucis. Insofern ist die >Inkorporation des Textes durch die kirchlichen Institutionen (Tradition, Amtskirche, Lehramt, Theologie) eine Ermächtigung ex post. Eine diese Ermächtigungsgeschichte unterlaufende Frage wäre die nach der der paulinischen Deutung eigenen

ängstlichem und wütendem Affekt begegnet wird, ebenso. Und dass selbst lutherische Kirchen das Hauptamt entsorgen mögen durch kostengünstiges Ehrenamt, ist auch bekannt. Diese ekklesiologischen und institutionenpolitischen Fragen seien hier nur erwähnt, nicht hingegen ausgeführt. 
Macht, das heißt: nach ihrer argumentativen Kraft, textuellen Form, rhetorischen Plausibilität, Performanz - und nicht zuletzt ihrer Wahrheit.

Die größte Versuchung allerdings wäre, die Deutungsmachtfrage wie einen gordischen Knoten zu behandeln, indem man versucht, weder Deutung noch Macht gelten zu lassen, sondern deutungsmachtfrei nach der Wahrheit zu fragen. Dann wäre die bestechend einfache Antwort: die Wahrheit sei es, die den Text ermächtigt. Er ist mächtig (und ist das geworden und geblieben), weil er wahr ist. Nur - wer stellt das fest? Wird das behauptet oder bezeugt? Und wann, wo, für wen? Wäre das für alle Zeiten und Orte zu behaupten, hätte man es mit einer analytisch notwendigen Wahrheit zu tun, die in allen möglichen Welten zu aller Zeit wahr ist. Das ist scilicet nicht der Fall und würde das Wort vom Kreuz mit Plus und Minus verwechseln. Es wäre auch der Kontingenz des Kreuzes unangemessen (die weder >Beliebigkeit`noch >Notwendigkeit noch auch >Mehr als Notwendigkeit ist). ${ }^{49}$

Die Deutungsmachtfrage so >gordisch $>$ zu entscheiden, würde >Wahrheit ` (am Ort der Wissenschaft und Exegese oder Dogmatik) an die Stelle Gottes treten lassen und als dessen Pseudonym fungieren (oder als Metonymie). Man würde demselben Ermächtigungsmodell folgen. Gottes Macht macht den Apostel, Gottes Wahrheit bewahrheitet dessen Deutung, und die Macht seiner Wahrheit ermächtigt diese Deutung: Wortmacht durch Machtwort. Analoges gälte etsi Deus non daretur: die Macht der Wahrheit ermächtigt die Deutung. So schön wie schlicht - und entspannend einfach. Das Komplizierte und Beunruhigende ist, dass all diese Aspekte nur relational (perspektivisch und diachron) zu bestimmen sind: als Kraft auf, Macht über, Wahrheit für etc. Die Macht ist stets verspätet, von ihrer Wirkung her, ex post wirksame Macht. Für die Wahrheit gilt Analoges. Versteht man Macht zudem nicht ursprungs- oder handlungslogisch als Eigenschaft einer Person (oder eines Gottes oder Apostels), sondern modal, dann geht es um die Frage, was ermöglicht und eröffnet diese Macht?

Wahr wäre diejenige Deutungsmacht (Wortmacht) zu nennen, die ermöglicht, was per se unmöglich wäre; die inkludiert, was nicht zu inkludieren wäre; die vergibt, was nicht vergebbar ist etc. Wahrheit ist eine >folie d'impossible swirkliche Möglichkeit` zu bestimmen, bliebe unterbestimmt. Paulus' Wette geht darauf, sie sei eine wirkliche und wirksame Unmöglichkeit: Das heißt, sie eröffnet einen neuen Himmel und eine neue Erde. Aber dieser Anspruch ist nicht einfach > wahr oder falsch`, sondern wahr ist er, wenn er zur wirksamen Wahrheit wird. Das aber ist nicht deutungsfrei zu entscheiden. Insofern führt die Abkürzung über die Wahrheitsfrage zurück in die Komplikationen der Deutung und die Verstrickung in Machtfragen. Dabei ist notwendig zu unterscheiden: Deutung ist nicht alles was ist, auch wenn alles nur in, mit und unter Deutungen gegeben ist. Analog gilt: auch wenn Wahrheit nur in, mit und unter Deutung gegeben oder zugänglich ist. Um sich in

49 Vgl. Philipp Stoellger, Die Vernunft der Kontingenz und die Kontingenz der Vernunft. Leibniz' theologische Kontingenzwahrung und Kontingenzsteigerung, in: Ingolf U. Dalferth / ders. (Hg.), Vernunft, Kontingenz und Gott. Konstellationen eines offenen Problems, Tübingen 2000, 73-116. 
Deutungsmachtkonflikten zu orientieren, ist Wahrheit ein kritisches Regulativ. Aber die Macht einer Deutung allein auf deren Wahrheit zurückzuführen, wäre phänomenal blind. Daher befreit die Wahrheitsfrage nicht von den Komplikationen zwischen Deutung und Macht mit ihren Konflikten. 